\title{
X-linked adrenoleukodystrophy: Pathology, pathophysiology, diagnostic testing, newborn screening and therapies
}

\author{
Bela R. Turk ${ }^{1}$ | Christiane Theda ${ }^{2}$ | Ali Fatemi ${ }^{1}$ | Ann B. Moser ${ }^{1}$ \\ ${ }^{1}$ Hugo W Moser Research Institute, Kennedy Krieger Institute, Baltimore, MD, USA \\ ${ }^{2}$ Neonatal Services, Royal Women's Hospital, Murdoch Children's Research Institute and University of Melbourne, Melbourne, VIC, Australia
}

\section{Correspondence}

Ann B. Moser, Hugo W Moser Research Institute, Kennedy Krieger Institute, 707 N. Broadway, Baltimore, MD, USA.

Email: Mosera@kennedykrieger.org

\section{Funding information}

Equipment and partial salary support for $\mathrm{AM}$ and $\mathrm{AF}$ was provided by the Intellectual and Developmental Disabilities Research Centers at the Kennedy Krieger Institute and Johns Hopkins University, Grant/Award Number: NICHD U54HD079123

\begin{abstract}
Adrenoleukodystrophy (ALD) is a rare X-linked disease caused by a mutation of the peroxisomal $A B C D 1$ gene. This review summarizes our current understanding of the pathogenic cell- and tissue-specific roles of lipid species in the context of experimental therapeutic strategies and provides an overview of critical historical developments, therapeutic trials and the advent of newborn screening in the USA. In ALD, very long-chain fatty acid (VLCFA) chain length-dependent dysregulation of endoplasmic reticulum stress and mitochondrial radical generating systems inducing cell death pathways has been shown, providing the rationale for therapeutic moietyspecific VLCFA reduction and antioxidant strategies. The continuing increase in newborn screening programs and promising results from ongoing and recent therapeutic investigations provide hope for ALD.
\end{abstract}

\section{K E Y W O R D S}

clinical trials, inflammation, newborn screening, therapy, very long-chain fatty acids, X-linked adrenoleukodystrophy

\section{$1 \mid$ INTRODUCTION}

X-linked adrenoleukodystrophy, ALD, (MIM \#300100) is the most common peroxisomal disorder affecting both males and females with an estimated birth incidence of about 1/14,700 (Bezman et al., 2001; Moser et al., 2016). ALD is caused by a mutation in the $A B C D 1$ gene which encodes a peroxisomal
ATP-binding cassette transporter for very long-chain saturated fatty acids $\geq$ C22:0 (VLCFA) into the peroxisome for $\beta$-oxidation (Kemp et al., 2001). As of April 3, 2019, there are more than 2,707 mutations of $A B C D 1$ of which 812 are non-recurrent and 248 variants of unknown significance (https://adrenoleukodyst rophy.info/mutations-and-variants-in-abcd1). There is no phenotype/genotype correlation (Kemp, Berger, \& Aubourg, 2012).

\footnotetext{
Abbreviations: ALD, X-linked adrenoleukodystrophy; AMN, adrenomyeloneuropathy; BBB, blood-brain barrier; C26:0-LPC, C26:0lysophosphatidylcholine; CALD, cerebral adrenoleukodystrophy; $\mathrm{CH} 25 \mathrm{H}$, cholesterol 25-hydroxylase; ELOVL1, gene encodes ELOVL Fatty Acid Elongase 1; ER, endoplasmic reticulum; FA, fatty acid; HSCT, hematopoietic stem cell transplantation; 24-HC, 24-hydroxycholesterol; 25-HC, 25-hydroxycholesterol; 27-HC, 27-hydroxycholesterol; 7KC, 7-ketocholesterol; LC-MS/MS, liquid chromatography mass spectrometry; MRI, magnetic resonance imaging; NAC, N-acetyl cysteine; OPCs, oligodendrocyte precursor cells; PUFA, polyunsaturated fatty acids; ROS, reactive oxygen species; UPR, unfolded protein response; VLCFA, very long-chain fatty acids.
}

This is an open access article under the terms of the Creative Commons Attribution License, which permits use, distribution and reproduction in any medium, provided the original work is properly cited.

(c) 2020 The Authors. International Journal of Developmental Neuroscience published by John Wiley \& Sons Ltd on behalf of International Society for Developmental Neuroscience 
Most men and women with ALD have a slowly progressive spinal cord disease, adrenomyeloneuropathy, AMN, men, typically beginning in their 30s, and women beginning postmenopausal (Engelen et al., 2014; Huffnagel, Dijkgraaf, et al., 2019a). However, 35\%-40\% of ALD males may develop a rapidly progressive inflammatory cerebral demyelination peaking in the ages 3-10 years of age. About 20\% of adult males with AMN also develop cerebral disease that rapidly progresses to disability and death (van Geel, Bezman, Loes, Moser, \& Raymond, 2001). Additionally, the adrenal glands are commonly affected with a lifetime risk of adrenal insufficiency of $\sim 80 \%$ in ALD males (Huffnagel, Laheji, et al., 2019b).

Allogeneic hematopoietic stem cell transplantation, HSCT, can halt the cerebral demyelination if done early before neurological symptoms and before advanced brain disease occurs. Early diagnosis through family screening of at-risk males, and as of December 2013 in the USA, newborn screening has provided hope for successful treatment for ALD (Raymond, Moser, \& Fatemi, 2018). Adrenal insufficiency is rare in ALD females but early identification of adrenal disease will save the lives of ALD males who may succumb to adrenal crisis without stress hormone administration (Dubey et al., 2005; Huffnagel, Laheji, et al., 2019b; Kemp, Huffnagel, Linthorst, Wanders, \& Engelen, 2016).

Lipids containing VLCFA accumulate in all tissues; however, the brain, spinal cord, adrenal cortex and the Leydig cells of the testis have the greatest increase of VLCFA. VLCFA are mainly esterified with cholesterol and glycerophospholipids, resulting in pathology (Johnson, Schaumburg, $\&$ Powers, 1976). Studies show that other lipids such as free cholesterol, the oxysterols, gangliosides and the plasmalogens may also contribute to the pathophysiology of ALD. (Igarashi, Belchis, \& Suzuki, 1976b; Khan, Singh, \& Singh, 2008; Nury et al., 2017; Powers, 2005).

Understanding how the accumulation of VLCFA leads to adrenal insufficiency, the rapid inflammatory brain disease in cerebral ALD (CALD) and the gradual loss of function in spinal cord disease are some of the topics of current research in ALD. There are clinical trials of promising therapies for the slowly progressive spinal cord disease; however, to date, there are no established effective treatments. ALD has no phenotype/genotype correlation, nor can the course of the disease be predicted based on the levels of VLCFA, thus the search for modifier gene(s) continues (Kemp et al., 2012).

\section{2 | HISTORY OF ALD}

\subsection{Defining the phenotype}

The first case of cerebral ALD was published by Haberfeld and Spieler in 1910. They described a boy who had been well until the age of 3 or 4 years when he was noted to be hyperpigmented. At the age of 6 and 1/2 years, he became disturbed, lost speech, the ability to walk, and died at 7 years. Postmortem examination showed adrenal atrophy and extensive demyelination with perivascular accumulation of lymphocytes and plasma cells at the leading edge of the myelin lesion (Haberfeld \& Spieler, 1910). Schilder described several cases in 1912, 1913, 1924 and thus at that time ALD became known as Schilder's disease (Schilder, 1912, 1913, 1924). Simmerling and Creutzfeld published a case of ALD in 1923 (Siemerling \& Creutzfeldt, 1923). Fanconi et al., in 1963, proposed X-linked inheritance based on the analysis of 10 reported cases (Fanconi, Prader, Isler, Luethy, \& Siebenmann, 1963). Michael Blaw introduced the term adrenoleukodystrophy, ALD (Blaw, 1970). In 1976, Budka et al. and Griffin et al. separately reported a form of ALD that presented as a slowly progressive paraparesis in adults, now known as AMN (Budka, Sluga, \& Heiss, 1976; Griffin, Goren, Schaumburg, Engel, \& Loriaux, 1977).

\section{2 | Discovery of lipid and fatty acid abnormalities}

The pathological observations in ALD adrenal cortex, Schwann cells, testis and postmortem brain by Jim Powers, Herb Schaumburg and Anne Johnson led to the identification of the abnormal inclusions as cholesterol esters containing an excess of VLCFA (Johnson et al., 1976; Powers \& Schaumberg, 1974a; Powers \& Schaumburg, 1973, 1974b). The serendipitous and key demonstration of increased VLCFA content in brain cholesterol esters was made by M. Igarashi, a visiting scholar in the laboratory of Kunihiko Suzuki at Albert Einstein College of Medicine, New York. This was then confirmed by Yasuo Kishimoto, known for his expertise in brain fatty acid metabolism at the Eunice Kennedy Shriver Center for Mental Retardation, Waltham MA (Igarashi, Schaumburg, et al., 1976a; Moser, 2006). This discovery led to the diagnostic identification of ALD males and females by measurement of total lipid VLCFA in cultured skin fibroblasts, amniocytes and plasma in the early 1980s (Moser et al., 1981, 1980).

\subsection{Inheritance and genetic defect}

With this biochemical handle many ALD families were found including a family who was alssssso informative for the gene for glucose-6-phosphate dehydrogenase, G-6-PD, which maps to the terminal segment of the long arm of the X chromosome, Xq28. Linkage studies in this family showed that the gene for ALD also maps to Xq28 (Migeon et al., 1981). The locus was further defined in 1988 by 
Aubourg and Sack by studies in an ALD family where the ALD gene segregated with the gene for color blindness (Aubourg, Sack, \& Moser, 1988). In 1993, the ALD gene, $A B C D 1$, was identified by Mosser et al. (Mosser et al., 1993). The ABCD1 gene encodes the peroxisomal transmembrane protein, the $\mathrm{ABCD} 1$ protein, also known as ALDP. A member of the ATP-binding cassette (ABC) transport family, the $\mathrm{ABCD} 1$ protein has the structure of an $\mathrm{ABC}$ half-transporter and transports saturated straightchained VLCFA as CoA esters to the peroxisome where they are degraded via $\beta$-oxidation (Kemp, Theodoulou, \& Wanders, 2011).

\section{3 | CLINICAL FEATURES OF ALD}

Clinical presentation of X-linked ALD phenotypes are summarized in Table 1 . These phenotypes are commonly used to describe cerebral, adrenal and spinal cords and peripheral nerve involvement. While no genotype-phenotype correlation is known, phenotype shift to deadly cerebral disease is typically only seen in homozygous individuals. (From Moser, Smith, Watkins, Powers, \& Moser, 2001; Used with permission). Further details regarding clinical have been comprehensively published in multiple reviews (Dubey et al., 2005; Engelen et al., 2014; Huffnagel, Ballegoij, et al., 2019c; Huffnagel, Dijkgraaf, et al., 2019a; Huffnagel, Laheji, et al., 2019b; Moser et al., 2000; Raymond et al., 2018).

\section{4 | BIOCHEMISTRY OF ALD}

\section{1 | Peroxisomal metabolism of fatty acids in ALD}

The $A B C D 1$ gene encodes the peroxisomal transmembrane protein, the $A B C D 1$ protein, also known as ALDP. A member of the ATP-binding cassette (ABC) transport family, the $A B C D 1$ protein has the structure of an $A B C$ halftransporter and transports saturated straight-chain VLCFA as $\mathrm{CoA}$ esters to the peroxisome where they are degraded via $\beta$-oxidation. In ALD, the VLCFA accumulate in plasma and the cells of all tissues (Kemp et al., 2001). Only a small amount of VLCFAs are of dietary origin. The majority are the result of chain elongation by the ELOVL enzymes (Jakobsson, Westerberg, \& Jacobsson, 2006; Tsuji, Sano, Ariga, \& Miyatake, 1981). There are 7 ELOVL enzymes; however, ELOVL1, is the one responsible for the chain elongation of VLCFA (Ofman et al., 2010; Ohno et al., 2010).

Two other peroxisomal $\mathrm{ABC}$ transporters, $A B C D 2$ and $A B C D 3$ can assume overlapping functions with $A B C D 1$.
These are not mutated in ALD (Matsukawa et al., 2011). $A B C D 1$ and $A B C D 2$ are highly homologous and have an overlap in specificity for saturated and monounsaturated fatty acids. $A B C D 2$ expression is lacking in human fibroblasts; thus, the $10 \%-15 \%$ residual $\beta$-oxidation in ALD is most likely due to $A B C D 3$ (Wiesinger, Eichler, \& Berger, 2015; Wiesinger, Kunze, Regelsberger, Forss-Petter, \& Berger, 2013). Overexpression of either $A B C D 2$ or $A B C D 3$ in ALD fibroblasts was shown to be able to correct the biochemical defect (Kemp \& Wanders, 2010; Kemp et al., 1998).

The saturated straight-chain VLCFA are found in excess in ALD blood and most tissues esterified to glycerophospholipids, lysophospholipids, sphingolipids, acyl-CoAs and acyl-carnitines (Kemp \& Wanders, 2010; Moser et al., 2001; van de Beek et al., 2016). In adrenal cortex, testis and in demyelinating brain there are large amounts of VLCFA esterified to cholesterol (Igarashi, Schaumburg, et al., 1976a; Theda, 1988; Theda, Moser, Powers, \& Moser, 1992). Postmortem white matter from a patient with late onset ALD was obtained from different areas of the brain and classified according to the microscopic appearance as "intact" (occipital), "active" (posterior frontal) and "gliotic," (frontal). The lipid analyses in three areas, showed distinct differences in the lipid composition. There was a marked increase in cholesterol esters containing VLCFA only in the "active" area. The C24:0 fatty acid content of the gangliosides was increased in ALD white matter from the "active" and the "gliotic" areas, and only slightly increased in the "intact" area when compared with control. The white matter ganglioside results confirmed the results reported by Igarashi, Belchis, et al. (1976b). The total phospholipids were increased in all ALD white matter samples when compared with control white matter and the galactolipids were decreased. The most striking finding was increased VLCFA, with a C26:0 fatty 17-fold increase compared with control, in the phosphatidylcholine from the "intact" and the "active" white matter samples (Table 2 adapted from Theda et al., 1992 used with permission). These lipid analyses demonstrate that the increase in the phosphatidylcholine VLCFA precedes the onset of demyelination. Microcalorimetric studies have shown that the C26:0 excess disrupts membrane stability (Ho, Moser, Kishimoto, \& Hamilton, 1995). The VLCFA modified phosphatidylcholine in the myelin membrane may result in changes in the structural integrity of myelin and lead to immunological mediated destruction of myelin that is characteristic of cerebral ALD.

\section{2 | The role of cholesterol metabolism in the pathophysiology of ALD}

Interestingly, the organs most affected by a deficiency of $A B C D 1$, brain and adrenal, have the highest content of 
TA B L E 1 ALD Phenotypes

\begin{tabular}{|c|c|c|}
\hline \multicolumn{3}{|l|}{ ALD phenotypes } \\
\hline \multicolumn{3}{|l|}{ Phenotypes in males } \\
\hline $\begin{array}{l}\text { Childhood cerebral } \\
\text { (CCALD) }\end{array}$ & $\begin{array}{l}\text { Progressive behavioral, cognitive and neurologic deficit often leading to } \\
\text { total disability and death within } 4 \text { years of diagnosis. Pathologic hallmark is } \\
\text { inflammatory cerebral demyelination }\end{array}$ & $\begin{array}{l}31 \%-35 \% \text { Onset at } 3-11 \text { years } \\
\text { of age }\end{array}$ \\
\hline Adolescent cerebral & $\begin{array}{l}\text { Presentation \& pathology as in CCALD. Onset 11-21 years with somewhat } \\
\text { slower progression than CCALD }\end{array}$ & $\begin{array}{l}4 \%-7 \% \text { Onset } 11-21 \text { years of } \\
\text { age }\end{array}$ \\
\hline $\begin{array}{l}\text { Adrenomyeloneuropathy } \\
(\mathrm{AMN})\end{array}$ & $\begin{array}{l}\text { Characterized by weakness, spasticity, pain, bladder \& bowel dysfunction and } \\
\text { impaired movement often resulting in assistive device or wheelchair use. } \\
\text { Pathology includes slow progressive distal axonopathy with atrophy of the } \\
\text { spinal cord, and peripheral neuropathy }\end{array}$ & $\begin{array}{l}\text { Most adult males will develop } \\
\text { AMN Onset typically starting } \\
\text { in third-fourth decade of life }\end{array}$ \\
\hline Addison-only & $\begin{array}{l}\text { Primary adrenal involvement without apparent neurologic involvement. Most } \\
\text { will continue to develop AMN }\end{array}$ & Common in childhood \\
\hline Asymptomatic & $\begin{array}{l}\text { Biochemical and gene abnormality without demonstrable adrenal or neurologic } \\
\text { deficit. Detailed studies often show adrenal hypofunction or subtle signs of } \\
\text { AMN on examination in adulthood }\end{array}$ & $\begin{array}{l}\text { Common in childhood. } 50 \% \text { of } \\
\text { asymptomatic develop AMN } \\
\text { within } 10 \text { years }\end{array}$ \\
\hline \multicolumn{3}{|l|}{ Phenotypes in females } \\
\hline Asymptomatic & No evidence of adrenal or neurologic involvement & \\
\hline $\begin{array}{l}\text { Adrenomyeloneuropathy. } \\
\text { Mild, moderate and } \\
\text { severe }\end{array}$ & $\begin{array}{l}\text { Symptomatology resembles AMN in men, albeit with later onset and a slower } \\
\text { rate of progression }\end{array}$ & $\begin{array}{l}\text { Increases with age. Estimates of } \\
50 \%>40 \text { and ca. } 65 \% \text { by } 65\end{array}$ \\
\hline
\end{tabular}

cholesterol in the body. While some investigations into the involvement of cholesterol metabolism in ALD have been made, we propose that cholesterol transport dysfunction may play a pathogenic role in oxidative response and inflammatorymediated processes.

\subsubsection{Cholesterol metabolism in brain}

As lipoprotein-bound cholesterol from the circulation cannot cross the blood-brain barrier, BBB, the majority of brain cholesterol is synthesized in the brain with $70 \%$ stored in myelin as free cholesterol with a very slow turnover (half-life of approximately 5 years) and the rest in the plasma membranes of neurons (10\%) and glia cells $(20 \%)$ that turnover more rapidly (half-life of 5-6 months) (Dietschy, 2009; Petrov, Kasimov, \& Zefirov, 2016; Pfrieger \& Ungerer, 2011). A surplus of cholesterol in neurons and other cells is stored as esters, thus about $1 \%$ of brain cholesterol in the normal adult brain is cytoplasmic cholesterol esters in lipid droplets formed by increased acyl-CoA cholesterol acyltransferase 1 gene expression (ACAT1) in response to high levels of excess cholesterol in the ER. Neurotoxic agents and oxidative stress enhance ACAT1 activity which is more expressed in neurons than in glial cells (Bryleva et al., 2010; Karten, Campenot, Vance, \& Vance, 2006).

In the "active" demyelinating white matter of ALD brain, there is a marked excess of cholesterol esters containing VLCFA and a diminished amount of free cholesterol when compared to control white matter or "intact" ALD white matter (Igarashi, Schaumburg, et al., 1976a; Theda, 1988; Theda et al., 1992; Table 2 from Theda et al., 1992 used with permission). The normal level of cholesterol esters and abnormal VLCFA content in the "intact" ALD white matter indicate that the accumulation of VLCFA containing cholesterol esters in the "active" demyelinating white matter is a secondary phenomenon. The excess VLCFA in macrophages and microglia scavenged from myelin debris cannot be degraded due to the lack of ALDP. The increased ACAT1 activity in response to inflammation and oxidative 
TA B L E 2 Lipid Composition of Control and ALD White Matter Samples

\begin{tabular}{|c|c|c|c|c|}
\hline $\begin{array}{l}\text { Water content, total lipids and lipid composition of control } \\
\text { and adrenoleukodystrophy white matter samples }\end{array}$ & Control & ALD intact & ALD active & ALD gliotic \\
\hline Water content $(\%)$ & 73 & 65 & 75 & 89 \\
\hline Free cholesterol ( $\%$ of total lipids) & 29.7 & 25.2 & 3.9 & $25.3^{\mathrm{a}}$ \\
\hline Cholesterol ester (\% of total lipids) & Trace & 0.5 & 31 & $1.3^{\mathrm{a}}$ \\
\hline Galactolipids (\% of total lipids) & 36.6 & 31.3 & 22.9 & $4^{\mathrm{a}}$ \\
\hline Phosphatidylcholine (VLCFA as \% total fatty acid) & 1.57 & 10.36 & 16.66 & \\
\hline Phosphatidylethanolamine (VLCFA as \% total fatty acid) & 0.12 & 1.82 & 0.72 & \\
\hline Phosphatidylserine (VLCFA as \% total fatty acid) & 2.49 & 0.73 & 1.08 & \\
\hline
\end{tabular}

${ }^{\mathrm{a}}$ Triglycerides and free fatty acids: $28.1 \%$ of total lipids.

stress leads to increased cholesterol esters with VLCFA (Igarashi, Schaumburg, et al., 1976a; Ramsey \& Davison, 1974; Reinicke, Knoll, Pretorius, Steyn, \& Simpson, 1985; Yao \& Dyck, 1981). The concentration of brain cholesterol esters is usually maintained at a low level as cholesterol hydrolases can convert the esters back to unesterified cholesterol; however, there is very low activity of the cholesterol ester hydrolases toward cholesterol esters with VLCFA (Ogino \& Suzuki, 1981).

\subsection{2 | Cholesterol metabolism in ALD adrenal cortex and Leydig cells}

There is a marked excess of cholesterol esters containing VLCFA in ALD adrenal cortex and Leydig cells (See Section 6.3).

\subsection{3 | Oxidized cholesterol species in ALD}

Oxidized cholesterol species in ALD may play a role in inflammation (See Section 5.5).

\subsection{4 | Cholesterol transport in ALD}

Excess cholesterol can also be transported out of the brain after converting to either 27-hydroxy cholesterol, 27-HC, by the mitochondrial enzyme CYP27A1 or to 24-hydroxy cholesterol, 24-HC, by the plasma membrane enzyme CYP46A1. 27-HC and 24-HC are the forms of cholesterol that can cross the blood-brain barrier, BBB. Increased permeability of the BBB to sterol molecules is related to BBB impairment (Saeed et al., 2014). 24-HC is $30-1500$-fold higher in the brain than any other organ except the adrenal. Of interest to our understanding of the ages when there is greatest risk of development of childhood cerebral ALD is the fact that in human plasma the ratio of $24-\mathrm{HC}$ to cholesterol is 5 times higher in the first decade of life than the sixth (Lütjohann et al., 1996; Dietschy and Turley, 2004; Saeed et al., 2014). The mitochondria of non-nerve cells, including the astrocytes, microglia and macrophages, have the enzyme CYP46A1 which can be upregulated by reactive oxygen species, ROS, in response to stress. The 24-HC after crossing the BBB can activate Liver X receptor, LXR (Anchisi, Dessi, Pani, \& Mandas, 2012; Petrov et al., 2016).

In 2015, the Bao-Liang Song research group demonstrated that cholesterol transport is abnormal in ALD fibroblasts and in the Abcd1 mouse model for ALD as well as in other peroxisomal disorders. Low-density lipoprotein (LDL) — derived cholesterol was transported from the lysosome to the peroxisome in a manner that depended upon lysosomal synaptotagmin VII binding to the peroxisomal lipid phosphatidylinositol 4, 5-bisphosphate $\left[\mathrm{PI}(4,5) \mathrm{P}_{2}\right]$ on the peroxisomal membrane (Chu et al., 2015; Hu et al., 2018; Islinger, Voelkl, Fahimi, \& Schrader, 2018; Jin, Strunk, \& Weisman, 2015; Luo, Jiang, Yang, \& Song, 2018; Luo, Liao, Xiao, \& Song, 2017; Stefan et al., 2017). While these findings were initially called into question by van Veldhoven et al. in a letter to the editor (van Veldhoven, Baes, \& Fransen, 2015), correctly identifying an error in Chu et al.'s method, a recent follow-up publication (Xiao et al., 2019) validates the initial Chu et al. (2015) findings.

As cholesterol is an important component of many cellular membranes and is also the substrate for the synthesis of bile acids, steroid hormones and regulating oxysterols, disruption of cholesterol transport may have widespread consequences in cholesterol homeostasis (Diotel et al., 2018; McDonald \& Russell, 2010; McMillan \& DeMorrow, 2016). 


\section{5 | OXIDATIVE AND}

ENDOPLASMIC STRESS AND

INFLAMMATION IN ALD

Even in the early pathological reports of the cerebral form of ALD, the role of inflammatory changes in cerebral tissues was discussed (Powers, Liu, Moser, \& Moser, 1992). With the advanced understanding of oxidative and inflammatory processes over the past decades, these have been explored in more detail in ALD.

\section{1 | Longer fatty acid chains directly induce apoptosis via endoplasmic reticulum, ER, stress response pathways}

The unfolded protein response, UPR, is a cell mechanism to maintain homeostasis which can induce apoptosis when the cell is under stress. UPR is distinguished by the action of three ER-located transmembrane receptors (protein kinase RNA-like endoplasmic reticulum kinase [PERK], activating transcription factor [ATF6] and inositol requiring kinase [IRE1]), which regulate these events in concert. VLCFA induced ER stress in human ALD fibroblasts, correlates with the FA chain length (van de Beek et al., 2017). Equimolar concentrations of increasing length FA, of methylated C16:0, C18:0 and C20:0 do not induce ER stress, but the methyl esters of the VLCFA, C22:0, C24:0 and $\mathrm{C} 26: 0$ do so in an increasing manner with $\mathrm{C} 26: 0$ inducing the highest ER stress marker XB1 $1_{\mathrm{s}}$ mRNA, an active transcription factor for UPR (Maly \& Papa, 2014). Consistent with VLCFA induced ER stress seen in cell culture, the PERK pathway is shown to be activated in the spinal cord of $A B C D 1$ knockout mice and brain and fibroblast samples from ALD patients (van de Beek et al., 2017). Both antioxidant and tauroursodeoxycholic, TUDCA, bile acid treatments of X-ALD mice prevent ER stress activation and halt subsequent axonal neurodegeneration (Launay et al., 2017; Tabak, Braakman, \& Zand, 2013). Both the antioxidant and TUDCA bile acid therapies are FDA approved and offer some hope for treatment of the UPR in AMN patients (Launay et al., 2017).

\section{2 | Fatty acids modulate mitochondrial function and increase radical generation}

Mitochondria and peroxisomes are critical organelles for ROS generation. Control and $A B C D 1$-astrocytes do not show different energy-dependent parameters (ROS generation, mitochondrial membrane potential (MMP), ADP-dependent respiration), suggesting that $A B C D 1$ has no direct effect on functional mitochondrial parameters
(Kruska, Schonfeld, Pujol, \& Reiser, 2015). Exposure to VLCFAs C22:0, C24:0 and C26:0 increases ROS generation in both control and $A B C D 1$ knock out astrocytes (Kruska et al., 2015).

There are multiple identified mechanisms of lipid induced modulation of mitochondrial function and related downstream effects. First, C22:0 is shown to modulate the internal mitochondrial membrane (IMM) by inducing mild uncoupling causing an increase in resting respiration. Second, fatty acids impair electron transport and inhibit F0F1-ATP synthase plus adenine nucleotide translocase, impairing respiration (Kruska et al., 2015). Finally, the FA-induced impairment of electron transport is well established and hypothesized to be due to membrane destabilization by the incorporation of VLCFAs, and/or by dissociation of cytochrome c from the IMM (Di Paola, Cocco, \& Lorusso, 2000; Korge, Honda, \& Weiss, 2003; Reiser, Schonfeld, \& Kahlert, 2006). FAinduced impairment of calcium homeostasis is chain length dependent, seen by $\mathrm{C} 20: 0$ and not C16:0, inducing ROS generation leading to rapid cell death of rat astrocytes (Hein, Schonfeld, Kahlert, \& Reiser, 2008). C22:0, C24:0 and C26:0 have been shown to greatly increase calcium in rat glial cells, with $\mathrm{C} 22: 0$ and partially $\mathrm{C} 24: 0$ proving detrimental to the inner mitochondrial membrane and inhibiting phosphorylating respiration.

\section{3 | VLCFA-induced radical generation leads to cell death}

Oxidative stress is understood as an imbalance between the production of reactive oxygen species and antioxidant systems. The brain provides relatively low levels of antioxidant defense with high contents of lipid moieties such as polyunsaturated fatty acids (PUFA) and catecholamines which are especially susceptible to free radicals (Halliwell \& Gutteridge, 2015). C26:0 is shown to induce DNA damage in C6 rat glial cells, with rescue effects seen via antioxidant co-culture (Marchetti et al., 2018).

While rigorous studies have underlined the role of free fatty acids in pathology, levels of C26:0 or similar VLCFA have not been shown to correlate to disease severity, differentiate or predict phenotype. However, plasma and cellular antioxidant capacity and ROS generation have been retrospectively associated to disease phenotype (Kemp et al., 2012).

\subsection{Antioxidant levels and the triglyceride metabolism are protective and high in AMN, not cerebral ALD}

An Increase in free radical levels and a lowered antioxidant capacity in human ALD blood plasma have been shown, with 
cerebral patients showing depleted levels of total glutathione (Turk et al., 2017; Vargas et al., 2004). This reduced antioxidant defense is also seen in AMN fibroblast and erythrocytes (Vargas et al., 2004), with higher amounts of DNA damage induced by increased radicals in AMN leukocytes (Marchetti et al., 2015).

Distinguishing markers between AMN and cerebral ALD is of critical importance, in both understanding the pathology and in creating a predictive biomarker for the cerebral form of ALD. Lipid and transcriptomics performed in human ALD fibroblasts revealed the differences between AMN and childhood CALD metabolism, suggesting that an increased triglyceride metabolism plays a protective role in AMN which is absent in cerebral disease (Lee et al., 2019). The pathways decreased in cerebral ALD were related to typical lipids and not VLCFAs (Lee et al., 2019). In AMN, anabolism in sphingolipid pathways including sphingomyelin and glycosphingolipid were downregulated and catabolism up-regulated. In AMN, the upregulated triacylglycerol metabolism is interesting, as triglycerides have shown neuroprotective effects against fatty acid-induced lipotoxicity (Listenberger et al., 2003) by keeping some excess saturated or monounsaturated fatty acids in lipid droplets and preventing the induction of necroptosis in oligodendrocytes and astrocytes (Hein et al., 2008; Parisi, Li, \& Atilla-Gokcumen, 2017). Triglycerides containing PUFAs limit toxicity by preventing PUFA-phospholipids from undergoing oxidation and increasing oxidative stress (Jarc et al., 2018; Li, Sancak, Frasor, \& Atilla-Gokcumen, 2018). One repeated question is whether these protective mechanisms are absent in cerebral patients before the onset of disease, and may serve as a predictive biomarker, or change as a result of or as a cause of cerebral disease onset. The importance of robust natural history studies in the AMN population including tissue sampling is highlighted by these findings.

Early oxidative damage to proteins of the spinal cord in the $\mathrm{Abcdl}^{-}$mouse was detected at 3.5 months of age, well before onset of symptoms. Bovine Serum Albumin, BSAC26:0 fatty acid was added to cultured fibroblasts from ALD and controls and showed increase of reactive oxygen species, ROS, decreased levels of glutathione and diminished mitochondrial membrane potential in ALD cells but not in controls. Cells cultured in the presence of the lipid antioxidant, $\alpha$-tocopherol, showed a reduction in oxidative damage. This experimental data led to the antioxidant trial in AMN patients (Fourcade et al., 2008).

\section{5 | Oxidized cholesterol species may contribute to inflammation}

Oxidative stress causes the oxidation of cholesterol leading to the formation of cholesterol oxide derivatives oxidized at C7; 7-ketocholesterol (7KC), 7 $\beta$-hydroxycholesterol and $7 \alpha$-hydroxycholesterol. $7 \mathrm{KC}$ was found to be increased in plasma from ALD patients. Addition of $7 \mathrm{KC}$ to the culture media of BV-2 cells, the murine model of glial cells, induces changes in peroxisomal functions. $7 \mathrm{KC}$ induces overproduction of $\mathrm{H}_{2} \mathrm{O}_{2}$ and $\mathrm{O}_{2}^{-}$and several peroxisomal modifications: decreased Abcd1, Abcd2, Abcd3, Acox1 and Mfp2 mRNA and protein levels, increased catalase activity and decreased Acox1 activity. These findings suggest that high levels of $7 \mathrm{KC}$ in ALD plasma could intensify brain damage (Nury et al., 2017).

The synthesis of 25-hydroxycholesterol, 25-HC, is catalyzed by the enzyme cholesterol 25-hdroxylase, $\mathrm{CH} 25 \mathrm{H}$, which uses cholesterol and molecular oxygen as substrates and NADPH as a cofactor. $25-\mathrm{HC}$ has potent and wide-ranging effects in the immune system including the differentiation of monocytes to macrophages (McDonald \& Russell, 2010).

Increased expression of $\mathrm{CH} 25 \mathrm{H}$ was found in primary fibroblasts in one out of three AMN and in all three CALD subjects when compared with controls. The levels of 25-HC were increased in all CALD cell lines. The authors also generated oligodendrocyte precursor cells, OPCs, from controls, AMN and CALD subjects. Consistent with the findings in primary cells, $\mathrm{CH} 25 \mathrm{H}$ mRNA levels were significantly higher in the CALD-OPCs than control and AMN OPCs (Jang et al., 2016). Exogenous addition of $1 \mu \mathrm{M} 25-\mathrm{HC}$ to CALD fibroblasts and OPCs led to a reduction in the C26/22 ratio. The 25-HC was found to downregulate ELOVL1 as well as activating LXR (Jang, Lee, Song, Kim, \& Min, 2019).

\section{6 | CELL - AND TISSUE-SPECIFIC PATHOLOGY}

\section{1 | Pathology and biochemical changes in the ALD brain}

Males and females with ALD are born with normal brain function. Myelination occurs normally and there is no developmental delay (Berger, Forss-Petter, \& Eichler, 2014). However, about $60 \%$ of ALD males develop a rapidly fatal demyelinating disease, with about $35 \%$ occurring in childhood between 3 and 10 years, about 5\% in adolescence, before the onset of spinal cord disease and another $20 \%$ as adults after years of spinal cord disease.

In normal appearing white matter of postmortem brains of ALD cases, a 17-fold excess of C26:0 was found in phosphatidylcholine compared with white matter of controls (Theda et al., 1992). Sharp, Johnson, and Poulos (1991) also found an excess of C30:0, C32:0 and C34:0 in phosphatidylcholine. The other phospholipids, cholesterol esters, triglycerides and the sphingolipids either had normal levels, or less than a twofold elevation (Theda et al., 1992). The presence of saturated 
VLCFA in phosphatidylcholine in myelin may lead to instability and inflammation. The VLCFA desorb much slower than normal dietary fatty acids, FA, from both albumin and protein-free lipid bilayers. As VLCFA accumulate due to impaired peroxisomal $\beta$-oxidation and enhanced FA elongation, elevated levels of VLCFA in membranes could alter structure and function in myelin (Ho et al., 1995).

The initiation of demyelination is still not well understood. There is no phenotype/genotype correlation as all forms of ALD occur with the same mutation in the $A B C D 1$ gene, within the same kindred and even differing time of onset in monozygotic twins (Di Rocco, Doria-Lamba, \& Caruso, 2001; Korenke et al., 1996). The levels of VLCFA in cultured cells and blood are the same when comparing AMN and cerebral ALD, CALD. CALD is rare in ALD females and the few reported cases are due to a Xq27-ter deletion of the non-mutated $\mathrm{X}$, or skewed $\mathrm{X}$-inactivation favoring the mutated X (Hershkovitz et al., 2002; Maier et al., 2002; Migeon et al., 1981). However, the amounts of VLCFA levels in normal appearing white matter were found to be higher in CALD compared with the levels in pure AMN (Asheuer et al., 2005). The study of oligodendrocytes derived from pluripotent stem cells from CALD accumulated more VLCFA than those derived from AMN patients (Jang et al., 2019). The blood-brain barrier may be leaky secondary to oxidative stress caused by increased levels of saturated VLCFA in myelin and cellular membranes (Lauer et al., 2017). In vitro studies suggest lack of $A B C D 1$ causes endothelial dysfunction preceding the accumulation of VLCFA (Kemp et al., 2016; Musolino et al., 2015). Early presence of contrast enhancement on magnetic resonance imaging, MRI, after brain contusion suggest that the disruption of the blood-brain barrier maybe the trigger for inflammatory demyelination (Aubourg, 2015; Raymond et al., 2010). Thus, monocytes and activated macrophages can enter the brain to scavenge cellular and myelin debris. ALD patients have normal capacity for macrophage differentiation and phagocytosis; however, they are pro-inflammatory skewed in both CALD and AMN (Aubourg, 2015; Musolino et al., 2015; Musolino, Rapalino, Caruso, Caviness, \& Eichler, 2012). ABCDl deficiency leads to incomplete establishment of anti-inflammatory responses of macrophages possibly contributing to the rapidly progressive demyelination in CALD (Weinhofer et al., 2018).

The demyelination begins usually in the splenium of corpus callosum where the white matter fiber bundles are most tightly packed and spreads outward into the periventricular white matter (Powers et al., 1992; Schaumburg, Powers, Raine, Suzuki, \& Richardson, 1975; Schaumburg, Powers, Suzuki, \& Raine, 1974). This is the area where the oligodendrocytes express the highest levels of ABCD1 (Lauer et al., 2017).

Interestingly, the corpus callosum white matter microstructure has more recently been shown to be the most sensitive region to repetitive head trauma in competitive sports players, who were clinically unremarkable and cognitively unaffected. Changes in diffusion tensor imaging metrics were seen after one season of college-level American football (Koerte et al., 2015; McAllister, 2014) and metabolic reductions in the $\mathrm{N}$-acetylaspartate/creatine-phosphocreatine ratio $(\mathrm{NAA} / \mathrm{Cr})$ in the corpus callosum, measured by single-voxel MR spectroscopy were seen in subclinical hockey players. These changes indicate a relationship between head impact exposure and white matter microstructural changes. As traumatic brain injury has been shown to induce cerebral disease in ALD, one may speculate that biomechanically induced torsion stresses upon the intra-hemispheric callosal connection under regular physical activity levels may predispose the location as more susceptible to initial blood brain barrier breakdown by causing microvascular endothelial damage constituting a possible longitudinal "hit" in the multiple hit model of cerebral disease onset (Singh \& Pujol, 2010).

There are marked changes in the lipid profile of ALD brain tissue when active demyelinating areas are analyzed in postmortem tissue. The VLCFA are enriched in cholesterol esters, predominately located in invading monocytes/macrophages entering the brain following the opening of the blood-brain barrier (Schaumburg et al., 1974). The myelin lipids, the phospholipids, sphingomyelin, cerebrosides, sulfatides, gangliosides and the proteolipid protein show an increased VLCFA (Bizzozero, Zuniga, \& Lees, 1991; Kishimoto et al., 1984; Theda et al., 1992). The anti-inflammatory plasmenylethanolamines (PlsEtn) are markedly decreased and there are increased levels of reactive lipid aldehydes and oxidized proteins leading to elevations of reactive oxygen species, ROS (Khan et al., 2008; Theda et al., 1992). The reduction of PlsEtn in CALD brain may be due to the increased need of the anti-inflammatory polyunsaturated fatty acids stored in the sn2 position of PlsEtn and released by phospholipase A2, and the decreased peroxisomal synthesis of PlsEtn, in part, by the lack of acetyl CoA generated by peroxisomal $\beta$-oxidation (Farooqui, Ong, \& Horrocks, 2003; Hayashi \& Oohashi, 1995).

The three-hit hypothesis describing the pathomechanisms of CALD is: (a) the metabolic defect including an increase in VLCFA leading to axonal degeneration and oxidative stress. (b) Neuroinflammatory processes, which may stem from environmental, stochastic, genetic or epigenetic factors resulting in macrophage infiltration and production of higher levels of inflammatory mediators. (c) After macrophage production of pro-inflammatory cytokines and chemokine mediators cause loss of peroxisomal functions including VLCFA oxidation and this leads to greater accumulation of VLCFA (Singh $\&$ Pujol, 2010). Here, the macrophages and microglia which have taken up the myelin debris cannot degrade the overabundant VLCFA and thus the cascade of metabolic stress and loss of myelin continues. 


\section{2 | Pathology and biochemical changes in spinal cord of AMN patients}

Most men with ALD will develop slowly progressive myeloneuropathy in their 20 s or 30 s. About $65 \%$ of ALD women will also develop symptoms of spinal cord disease by the age of 65 , although some women may have symptoms in their 20s (Engelen et al., 2014). Early symptoms of AMN are loss of sensation in the legs followed by the development of a spastic gait and bladder and bowel incontinence. The peripheral nerves are also involved, and in ALD women there is often dysesthesia (van Geel et al., 1996). The increased VLCFA in the myelin lipids of the AMN spinal cord cause oxidative stress and impaired mitochondrial function that contribute to the myeloneuropathy through a failure of ATP-dependent axonal transport (Fourcade et al., 2008; Wanders, 2014). This leads to a distal dying-back axonopathy. The peripheral nerves are also involved, with primary axonal degeneration in most AMN men and 80\% of women. Histological analyses of the dorsal root ganglia from AMN spinal cord did not show apparent neuronal loss, necrosis or apoptosis, a non-inflammatory myopathy (Powers, DeCiero, Ito, Moser, \& Moser, 2000). On ultrastructural analysis, many neurons contain mitochondria with lipid inclusions leading to the failure of ATPdependent axonal transport in AMN spinal tracts. There was loss of large axons that were replaced with smaller axons. Impaired mitochondrial function may contribute to the dying back axonal degeneration (Powers et al., 2001). Recently, Gong et al. described the expression of "eat-me" molecules MFGE8 and TREM2 preceding complement activation and synapse loss in the spinal cord. C26:0-LPC added to ABCD1-deficient microglia in culture induced MFGE8 expression, aggravating phagocytosis leading to neuronal injury (Gong et al., 2017).

\section{3 | Pathology and biochemical changes in ALD adrenal cortex and Leydig cells}

The lifetime incidence of adrenal disease in ALD males is about $80 \%$ with $46.7 \%$ developing adrenal hormone deficiency in childhood, 6 months -10 years of age, $28.6 \%$ ages $10-40$ years and only 5.6\% after the age of 40 years (Huffnagel, Laheji, et al., 2019b). The fetal adrenal in ALD males has the abnormal pathology and biochemistry found in adrenals of postnatal males with ALD. In the adrenal cortex, there is striking accumulation of cholesterol esters with VLCFA. These are increased to $30 \%$ in ALD versus 1\%-3\% in controls (Igarashi, Schaumburg, et al., 1976a; Moser et al., 1982). Cholesterol esters containing VLCFA are very poor substrates for the cholesterol ester hydrolases (Ogino \& Suzuki, 1981). This leads to their accumulation within the cell in the form of lamellar inclusions and to cell dysfunction and cell death (Powers, Schaumburg, Johnson, \& Raine, 1980). When C26:0 and C24:0 fatty acids were added to the culture media of primary adrenal cortical cells in a $5 \mu \mathrm{M}$ concentration there was increased membrane microviscosity of the cells and a reduction to adrenocorticotropic hormone, ACTH, stimulation (Whitcomb, Linehan, \& Knazek, 1988). This study suggests that there may be direct toxicity of the VLCFA. There is also evidence that due to the accumulation of cholesterol esters with VLCFA, there may not be enough free cholesterol available for synthesis of the steroid hormones (Powers, 1985). VLCFA accumulate in the zona reticularis and zona fasciculate with sparing of the zona glomerulosa leading to primary cortisol insufficiency and androgen deficiency. The site of adrenal dysfunction is in good agreement with the fact that $\mathrm{ABCD} 1$ protein is found in the adrenal cortex but not in the adrenal medulla, while ABCD2 shows the opposite distribution (Troffer-Charlier et al., 1998). The VLCFA in the cell membranes may also interfere with ACTH and gonadotropin binding to their receptors (Burtman \& Regelmann, 2016; Huffnagel, Laheji, et al., 2019b). Similar biochemical changes and pathology are found in the Leydig cells of the testes leading to defective hormonogenesis. Thus, men with ALD may have clinical and subclinical hypogonadism and impaired sexual function although many have fathered children. Low levels of testosterone with elevation of luteinizing hormone, $\mathrm{LH}$, and follicle-stimulating hormone, FSH, concentrations are consistent with defective testicular function (Powers \& Schaumburg, 1981). Adrenal function should be monitored in all ALD males and can be corrected with administration of adrenal hormones, with stress dosing during illness, accident or surgery. Adrenal insufficiency is rare in females with ALD (Dubey et al., 2005; Engelen et al., 2014; Huffnagel, Laheji, et al., 2019b).

\subsection{Searches for modifier genes}

There is considerable interest in finding genes that modify the phenotype of ALD. A polymorphism in CYP4F2, the gene that is responsible for peroxisomal $\omega$-oxidation of VLCFA to very long-chain dicarboxylic acids was found to increase the risk of development of childhood onset CALD by decreasing the clearance of VLCFA through $\omega$-oxidation (van Engen et al., 2016). Eleven microRNAs were identified that had different expression for CALD and AMN and one of them, MiR196a, was found to inhibit the expression of two inflammatory signaling factors as well as ELOVL1 (Shah \& Singh, 2017).

\section{7 | EXPERIMENTAL MODELS}

\section{1 | Animal models}

Animal models provide a necessary platform in understanding the pathology of disease and serving as a test bed in demonstrating the biological significance of novel therapeutic interventions. In commonly used genetically malleable 
species such as the drosophilae, mouse and zebra fish, the equivalent $A B C D 1$ gene has been successfully targeted to generate knock-out models, each providing a unique strength and limitation (Forss-Petter et al., 1997; Gordon, Valdez, \& Letsou, 2018; Kobayashi, Shinnoh, Kondo, \& Yamada, 1997; Lu et al., 1997; Strachan et al., 2017).

\subsection{1 | Drosophilae models}

In drosophilae models, $C G 2316$ has been identified as a sole homolog of human $A B C D 1$, termed $d A B C D$. Transgenic $d A B C D$ transgenic flies survive to adulthood with a neurodegenerative phenotype neuron and glia loss. A same phenotype is seen in long-/very long-chain acyl-CoA synthetase gene $b g m$ models. Disruption of $d A B C D$ in neurons results in retinal defects, which are not caused by the same alterations to glial cells. In the drosophilae model, environmental stress modifies penetrance and expressivity of neurodegeneration (Gordon et al., 2018). Interestingly, here the phenotype is rescued (reduction of retinal damage) with diet supplementation by medium-chain-FA; however, supplementation by longchain FA does not exacerbate disease.

\subsection{2 | Zebra fish model}

A zebra fish model (Danio Rerio) with $A B C D 1$ mutants shows elevated VLCFA levels, with hypomyelination of the spinal cord, abnormal patterning and decreased numbers of oligodendrocytes and increased cell death. Functionally, the fish demonstrate impaired motor function and a decrease in overall survival. Induction of human ABCD1 expression in oligodendrocytes reduced embryonic apoptosis of these cells and improved motor function (Strachan et al., 2017).

\subsection{3 | Murine models}

In 1997, three mouse models for ALD, were developed separately by researchers in, Vienna, Austria, Fukuoka, Japan and Baltimore, USA (Forss-Petter et al., 1997; Kobayashi et al., 1997; Lu et al., 1997).

The $A b c d l$ deficient mouse is a well investigated yet challenging model. While biochemical defects have been measured early in life, with oxidative biomarkers present at as early as 3.5 months, the mouse does not develop the deadly cerebral phenotype seen in humans. As the Abcdl-deficient mouse most resembles the AMN phenotype, developing axonopathy and locomotor impairment at a very late 22 months of age (Pujol et al., 2002); it has been the model of choice for novel therapeutics targeting the spinal cord. A double-mutant $A b c d 1 / A b c d 2$ mouse exhibits higher VLCFA accumulation in the spinal cord (Pujol et al., 2004), higher levels of oxidative damage (Fourcade et al., 2010) and more severe locomotor impairment with earlier onset (Fourcade et al., 2008). In this mouse, axonopathy progression was halted and biochemical markers of oxidation and ER stress were ameliorated by antioxidant compound and TUCDA bile acid therapies. (Fourcade, Lopez-Erauskin, Ruiz, Ferrer, \& Pujol, 2014; Launay et al., 2017; Lopez-Erauskin et al., 2011) In the peripheral nerves of the $A b c d l$ mouse, Kleinecke demonstrated lysosomal storage and increased VLCFA in gangliosides of lipid rafts causing altered axonal Kv1 channels in Schwann cells leading to peripheral neuropathy which was age dependent (Islinger et al., 2018; Kleinecke et al., 2017).

Double-knockout mouse models were developed with other PEX genes, the Pex7/Abcdl, and the $A b c d l$ with the peroxisome-deficient oligodendrocytes that do have some pathology resembling that in patients with ALD (Kassmann et al., 2007). The Pex7/Abcdl model shows demyelination in white matter suggesting that plasmalogens may have both structural and functional roles in membrane and cellular stability (Brites, Mooyer, Mrabet, Waterham, \& Wanders, 2009).

As ELOVL1 is the essential enzyme in chain elongation of C22:0 to C26:0. Transgenic mice overexpressing ELOVL1 in oligodendrocytes (Cnp-ELOVL1 ${ }^{ \pm}$) had a 25-fold higher elongation activity for C22:0-CoA. Double transgenic $A B C D 1^{y /-}$, Cnp-ELOVLI ${ }^{ \pm}$mice had C26:0 levels increased 20-fold in brain, 44-fold in adrenals, 90-fold in testes and increased in other organs more than what was found for the single knockout of $A B C D 1^{y /-}$. One of the interesting conclusions of this study was that oligodendrocytes are largely responsible for total VLCFA synthesis in the brain. In addition, the studies showed that the levels of C24:0-lysoPC, C26:0-lysoPC and C22:0-carnitine, C24:0-carnitine and C26:0-carnitine were increased in brain and spinal cord from $A B C D 1^{y /-}$ and $A B C D 1^{y /-}$, Cnp-ELOVLI ${ }^{ \pm}$mice (van de Beek et al., 2016).

\section{2 | Cellular model}

Recently a microglial model for ALD was produced by knocking out $A b c d l$ and $A b c d 2$ in BV-2 cells, murine microglial cells. These cells accumulate VLCFA and have lipid droplets and striated and whorled lipid inclusions (Raas et al., 2019).

\section{8 | DIAGNOSTIC TESTING FOR ALD AND THE DEVELOPMENT OF NEONATAL SCREENING}

\section{1 | Diagnostic testing for ALD}

Historically, the diagnosis of ALD in boys was established by neuroimaging following early symptoms of attention deficit 
and hyperactivity disorder, failure in school, difficulties in understanding language, behavior disturbances and decline in handwriting (Moser et al., 2001). In the early 1980s, the measurement of very long-chain fatty acids in plasma provided a reliable diagnostic test (Moser et al., 1981). It allowed that the diagnosis suspected from neuroimaging (initially computer tomography and later MRI) to be confirmed biochemically by measurement of plasma total lipid VLCFA (Moser et al., 1999). Once the $A B C D 1$ gene was known, the sequencing of the $A B C D 1$ gene was used diagnostically as analysis of the family $A B C D 1$ mutation improves the diagnosis of ALD women as the plasma VLCFA test has a $20 \%$ false negative rate (Boehm, Cutting, Lachtermacher, Moser, \& Chong, 1999).

Following the development of the whole blood spot liquid chromatography tandem mass spectroscopy (LC-MS/MS) measurement of C26:0-lysophosphatidyl choline, C26:0LPC, for the diagnosis of newborns with ALD, the Academic Medical Center in Amsterdam has shown that the C26:0-LPC assay accurately diagnoses males with ALD, and importantly offers an accurate diagnostic test for women with ALD, with a reported sensitivity of $100 \%$ in 49 females and 126 controls (Huffnagel et al., 2017).

In support of this finding, we present previously unpublished C26:0-LPC measurements by LC-MS/MS in 1/8" dry blood spot, DBS, in 189 controls and 117 ALD heterozygote females. Setting the diagnostic threshold at the maximum healthy control measurement $(0.1578 \mu \mathrm{Mol})$ for a specificity of 100, C26:0-LPC demonstrates a sensitivity of $94.87 \%$ $(95 \% \mathrm{CI}=89.17 \%-98.1 \%)$ in differentiating between healthy control and women with ALD, with an overlap seen in six measurements in the female group (Supporting Information Method S1 and Figure S1).

\subsection{The development of newborn screening for ALD}

Hematopoietic stem cell transplantation, HSCT is livesaving gold standard, initiated as soon as cerebral disease is discovered. However, as neurological deficits do not improve with therapy, improving diagnosis would allow for surveillance of cerebral disease and reduce potential residue (Mahmood, Raymond, Dubey, Peters, \& Moser, 2007; Moser et al., 2000). Thus, neonatal screening was proposed for ALD by Hugo Moser and colleagues in 2004. However, at that time there was no valid test for ALD using the newborn blood spot. Informed by analyses of lipids in normal appearing white matter of ALD brain, which showed that C26:0 was increased in phosphatidylcholine (Theda, 1988; Theda et al., 1992), the potential to diagnose ALD in blood phospholipid subfractions was investigated. In 2006 a first newborn screening test for ALD by measurement of C26:0lysophosphatidylcholine, C26:0-LPC in newborn dried blood spot was established (Haynes \& De Jesus, 2012; Hubbard et al., 2009, 2006; Raymond, Jones, \& Moser, 2007; Theda et al., 2014; Turgeon et al., 2015). After refining the LC-MS/MS assay of C26:0-LPC and several pilot studies, in December 2013, neonatal screening for ALD started in the state of New York. In February 2016, the Secretary of Human Health signed the recommendation to add ALD to the recommended uniform screening panel in the USA (Kemper et al., 2017; Moser et al., 2016). As of October 19, 2019, 14 states and the District of Columbia are screening all newborns for ALD, 3 states have ALD pilot screening, and more states are planning to start within the next year (Figure 1). In October 2019, the Netherlands plans to start an ALD pilot screening of all newborn males. The early detection of the biochemical abnormalities associated with ALD and AMN has proven to be reliable to detect those affected by the condition but also poses new ethical and clinical challenges (Kemper et al., 2017; Moser et al., 2016).

\section{ASSESSMENTS OF DISEASE SEVERITY}

With the advent of newborn screening (or when relatives are diagnosed), early confirmation of the biochemical and genetic abnormalities associated with the diagnosis of ALD/ AMN is possible. While the early, presymptomatic diagnosis of ALD/AMN might be quite distressing to the families of those affected, it is an important step to minimize morbidity and mortality. To be able to provide best evidence-based care for children and their families, especially with a focus on preventing the devastating advanced forms of CALD, the establishment of reliable imaging criteria and biomarkers that should trigger interventions is essential.

\section{1 | Adrenal function}

Adrenal dysfunction should be closely monitored in all males (Regelmann et al., 2018). Adrenal hormone therapy is successful at preventing severe illness or loss of life due to Addisonian crisis (Burtman \& Regelmann, 2016; Huffnagel, Laheji, et al., 2019b; Shulman, Palmert, Kemp, Lawson Wilkins, \& Therapeutics, 2007).

\subsection{Neuroimaging}

MRI with or without contrast enhancement is used to monitor presymptomatic males with ALD for early and progressive white matter changes (Liberato et al., 2019; Eichler et al., 2007; Loes et al., 2003). A semi-quantitative MRI severity score was developed by Daniel Loes, referred to as the Loes 


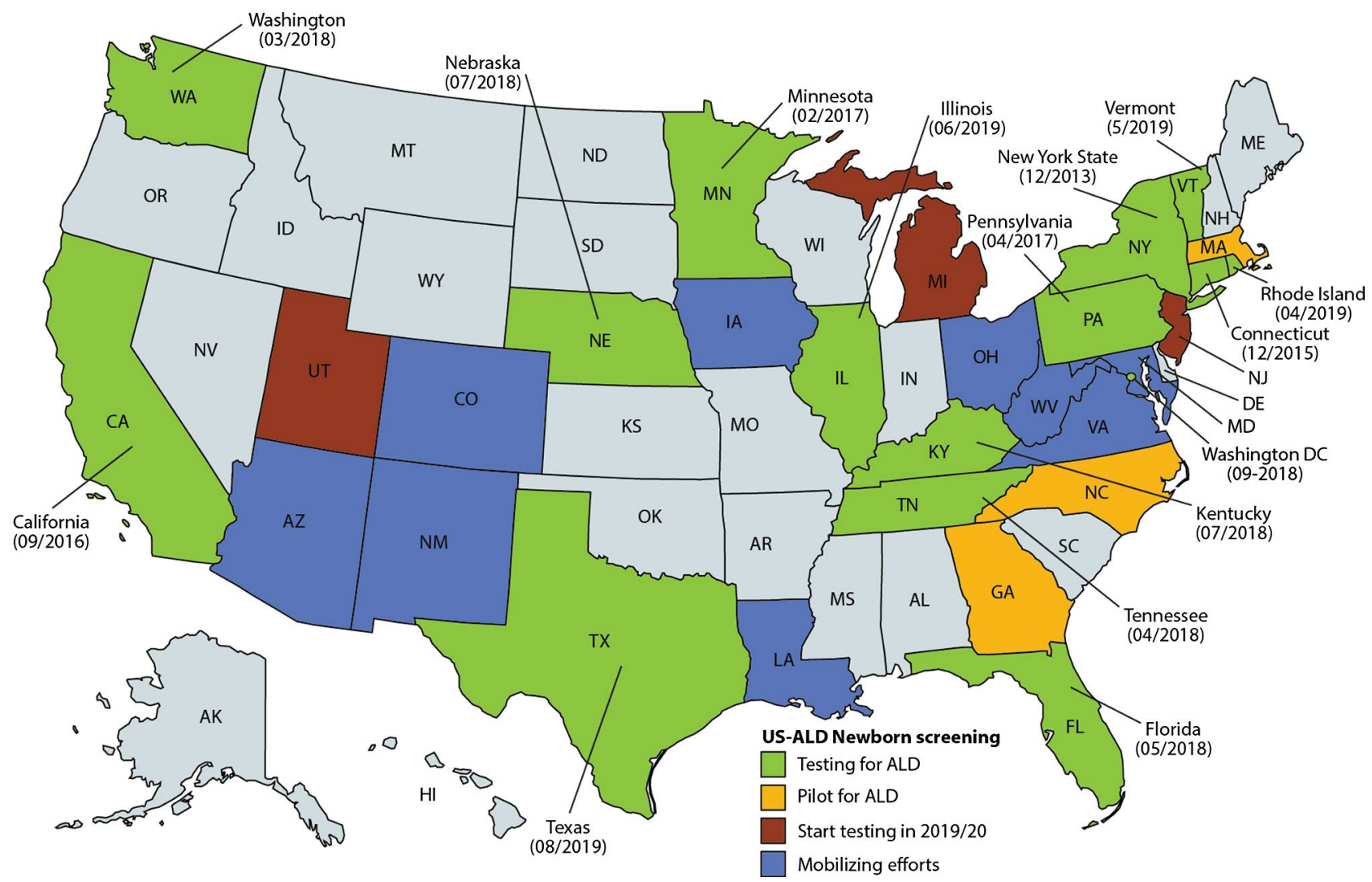

F I G U RE 1 ALD newborn screening in the USA as of October 19, 2019 (https://adrenoleukodystrophy.info)

score, with 0.5 or less for "normal" ranging to 34 at maximum severity. For those known to be affected by ALD (after newborn screening or through screening due to affected relatives), close monitoring by neuroimaging is recommended.

\section{3 | Other assessments}

Employed in the investigative setting, assessment of physical capabilities and measurements of walking speed, hip strength, vibration sense and nerve conductions studies has been used in assessing disease severity in AMN (Zackowski et al., 2006). A 2-year study of disease progression in males with AMN used Expanded Disability Status Score (EDSS), a Severity Scoring System for Progressive Myopathy (SSPROM), quantitative vibration measurement at hallux, the 6-min walk test and timed up-and-go to assess the progression of myelopathy (Huffnagel, Ballegoij, et al., 2019c).

\section{0 | STANDARD THERAPY FOR CHILDHOOD CEREBRAL ALD}

Currently, effective treatment for early brain disease, detected by MRI with contrast enhancement, is allogenic hematopoietic stem cell transplantation, HSCT. Ideal candidates for intervention are individuals with a Loes score of 9 or lower, without any neurologic deficits, who receive HLAmatched sibling or related donor HSCT. However, this intervention has a high-morbidity and long-term sequelae related to immunosuppression and graft versus host disease. It is important to note that disease progression continues for some 6-9 months following HSCT (Miller et al., 2011; Peters et al., 2004; Raymond et al., 2019). Importantly, adrenal dysfunction is not corrected following HSCT transplant for cerebral disease (Burtman \& Regelmann, 2016).

\section{1 | EXPERIMENTAL THERAPEUTIC TRIALS AND STRATEGIES}

\section{1 | Dietary therapies; Lorenzo's oil}

As the VLCFAs play a crucial role in the pathogenesis of ALD, the first trials to normalize the VLCFA in ALD through dietary restriction of VLCFA, followed by oleic acid alone and then Lorenzo's oil, a 4:1 mixture of oleic and erucic acid triglycerides, were tried, but all were without neurological or endocrine improvement (Moser et al., 2001). Lorenzo's oil together with 
a low-fat diet was given to 89 asymptomatic ALD boys in an open, non-placebo-controlled, trial. After a mean follow-up of 6.9 years, 24\% developed CALD; however, compared to historical data, the percentage of boys that would develop CALD was 37\% suggesting a protective effect (Moser et al., 2005). Studies in postmortem brain of CALD who were on Lorenzo's oil showed no evidence of erucic acid in brain lipids (Poulos, Gibson, Sharp, Beckman, \& Grattan-Smith, 1994; Rasmussen, Moser, Borel, Khangoora, \& Moser, 1994); however, later studies in rats showed that erucic acid entered the brain and was either degraded or chain elongated to nervonic acid (Golovko \& Murphy, 2006). The mechanism for Lorenzo's oil was thought to be by competitive inhibition of the chain elongation of saturated fatty acids by providing an excess of monounsaturated fatty acid precursors. The in vitro study of Lorenzo's oil in HeLa cells expressing high levels of ELOVL1, the enzyme that catalyzes the chain elongation of $\mathrm{C} 22$ to $\mathrm{C} 26$ fatty acids in the endoplasmic reticulum, showed that Lorenzo's oil strongly inhibits ELOVL1 (Sassa, Wakashima, Ohno, \& Kihara, 2014). Lorenzo's oil therapy is not FDA approved as a double-blind placebo-controlled trial has not seen successful completion. In open-label studies, Lorenzo's oil has not shown to halt or slow disease progression in AMN nor in CALD (Aubourg et al., 1993; van Geel et al., 1999; Rizzo, 1993).

\section{2 | Metabolic modulators}

One inhibitor of ELOVL1 is bezafibrate that showed reduced VLCFA in ALD fibroblasts (Engelen, Schackmann, et al., 2012a). However, in a clinical trial of administering bezafibrate to AMN men and women VLCFA in plasma, lymphocytes and dried whole blood spots were not lowered (Engelen, Tran, et al., 2012b).

Statins lower LDL cholesterol. In 1998 Singh et al. reported that ALD patients given lovastatin normalized their plasma VLCFA (Singh, Khan, Key, \& Pai, 1998). Another randomized double-blind crossover trial comparing lovastatin to placebo showed no normalization of C26:0 in ALD patients (Engelen et al., 2010).

Various studies have shown an upregulation of peroxisomal $\beta$-oxidation in cells from ALD subjects and the $A B C D 1$ mutant mouse model by upregulation of the $\mathrm{ABCD} 2$ protein and peroxisome proliferation. Normalization of $\mathrm{C} 24: 0$ levels in brain and C26:0 levels were lowered by $80 \%$ in Abcd1 mice after 6 weeks of feeding 4-phenyl- butyrate, 4PBA (Kemp et al., 1998).

Overexpression of Abcd2 in an Abcd1 knockout mouse normalizes VLCFA in spinal cord, sciatic nerve and adrenal gland (Pujol et al., 2004). However, to date there have not been clinical trials of 4PBA in ALD.

It was shown that thyroid hormone receptor agonist sobetirome increased Abcd 2 mRNA levels in brain and liver of wild-type mice. Adult $A b c d 1 \mathrm{KO}$ mice were treated with sobetirome for 12 weeks resulting in a lowering of C26:0LPC levels in plasma, brain, testes and adrenal tissue by $20 \%$ (Hartley, Kirkemo, Banerji, \& Scanlan, 2017). Other thyroid hormone agonists are currently being pursued as potential therapeutic candidates in ALD.

Morato et al. demonstrated that pioglitazone, a PPAR $\gamma$ agonist, halts axonal degeneration in the Abcd1 mouse by restoring mitochondria (Morato et al., 2013). Recently, a derivative of pioglitazone has been developed and is currently in being assessed in a multinational, placebo-controlled, randomized trial in AMN.

\section{3 | Anti-inflammatory strategies}

Anti-inflammatory drugs such as immunoglobulin, cyclosporine, cyclophosphamide and interferon-beta were tried to halt or reverse the cerebral inflammation (Moser et al., 2001). These drugs were not effective in halting the cerebral inflammation.

\section{4 | Antioxidant therapy}

A combination of multiple high-dose antioxidants was recently demonstrated to normalize biomarkers for oxidative damage and inflammation in a small open-label trial of adult patients with AMN (Casasnovas et al., 2019). There appeared to be a potential effect on the 6-min walk test, justifying larger placebo-controlled trials in future.

Several centers have utilized N-Acetyl cysteine (NAC) adjunct therapy for individuals undergoing allogeneic HSCT. One study showed individuals with more advanced MRI undergoing HSCT had improved survival with NAC therapy, not however demonstrating an improvement in residual neurologic deficit (Miller et al., 2011).

As with most neurologic disease, main pharmacodynamic challenges are in passing the blood-brain barrier and in the targeted delivery of a therapeutic compound. Recently, a nanoparticle polyamidoamine, PAMAM, dendrimer drug delivery platform conjugated to NAC (D-NAC), having shown rescue of motor impairments and inflammatory status in a neonatal rabbit model of cerebral palsy (Kannan et al., 2012), demonstrated targeted drug delivery into Abcdl mouse spinal cord microglia, and in ex vivo cerebral ALD peripheral blood monocytic patient cells stimulated by VLCFA (C26:0), normalization of antioxidant and inflammatory status (Turk et al., 2018).

\section{5 | Gene therapy}

In order to decrease the burden of morbidity of allogeneic HSCT, a trial of autologous HSCT with ex vivo lentiviral gene 
correction of CD34-positive stem cells is ongoing(Cartier et al., 2009; Eichler et al., 2017). Interim findings of this trial in 17 ALD boys with early stage brain disease who received the Lenti-D $A B C D 1$ gene therapy have been reported. No treatment death or graft versus host disease was seen. Fifteen of the boys survived; however, 1 died of rapid neurologic deterioration and the other, who had evidence of rapid disease progression on MRI, withdrew from the study to undergo allogenic stem cell transplantation and died of complications. All 15 boys who survived remained free of major functional disabilities at the 24-month follow-up. A longer follow-up and larger sample size is needed to confirm the efficacy and safety of $A B C D 1$ gene therapy with the Lenti-D lentiviral vector.

In addition to ex vivo lentiviral gene correction, in vivo adeno-associated virus 9 (AAV9)-based gene therapy is being pursued. Gong et al. have showed intrathecal delivery of an AAV9 carrying $A B C D 1$ in mice corrected VLCFA metabolism and behavioral outcomes (Gong et al., 2015). This therapeutic strategy may show promise for AMN due to the intrathecal delivery.

\section{6 | Other therapeutic strategies}

The screening of drug libraries for drugs that reduce the VLCFA in transformed human fibroblasts is currently being investigated (Schrifl, 2016). Redirecting the synthesis of saturated VLCFA to monounsaturated VLCFA, which are less toxic to membranes, by upregulating the enzyme StearoylCoA Desaturase-1 is another current avenue of research (van de Beek et al., 2019).

\section{2 | CONCLUSION}

This review of ALD summarizes our understanding of $A B C D 1$ - and VLCFA-related pathogenic mechanisms, and rationale they provide for current experimental therapeutic strategies. In ALD, the $A B C D 1$ mutation is shown to dysregulate manifold metabolic and immune pathways, inducing tissue- and cell-specific pathogenic processes. VLCFA is shown to both directly induce apoptotic pathways, and indirectly via ER and mitochondrial radical-related stress mechanisms. These mechanisms are shown to be chain length dependent, providing a rationale for a therapeutic approach in the reduction of specific VLCFA moieties.

Oxidative stress and antioxidant systems show phenotypic-specific dysregulation in ALD, suggesting therapeutic benefit by antioxidant strategies. Additionally, marked reduction in other endogenous antioxidants such as the peroxisomal, myelin-critical plasmalogen species seen in cerebral ALD brain tissue, may contribute further insight into underlying disease mechanisms. Promising results from an ongoing gene-therapy trial and recent antioxidant therapy investigations and the increase in newborn screening programs provide hope for patients with ALD.

\section{ACKNOWLEDGEMENTS}

We thank patients and their families for participation in the many studies and clinical trials described in this review. We are grateful for the helpful comments of our research collaborators and mentors as we prepared this review paper. We also thank the Aidan Jack Seeger Foundation, ALD Connect, the Leukodystrophy Care Network (LCN), Hunters Hope, Stop ALD, the United Leukodystrophy Foundation and Brian's Hope for their ongoing support in developing the guidelines for surveillance of ALD boys identified by newborn screening for ALD.

\section{CONFLICT OF INTERESTS}

Ali Fatemi, MD is on the safety monitoring board for Bluebird Bio, Stealth Biotherapeutics and a paid consultant to Calico Laboratories. Christiane Theda, $\mathrm{MD}, \mathrm{PhD}$ is the Co-Founder, Chief Medical Officer and a Company Director of Navi Medical Technologies Pty Ltd and Medical Advisor to Ventora Pty Ltd. These companies develop new biomedical devices unrelated to peroxisomal disorders and adrenoleukodystrophy. Bela R. Turk, MD and Ann B. Moser, BA have no conflict of interest.

\section{REFERENCES}

Anchisi, L., Dessi, S., Pani, A., \& Mandas, A. (2012). Cholesterol homeostasis: A key to prevent or slow down neurodegeneration. Frontiers in Physiology, 3, 486.

Asheuer, M., Bieche, I., Laurendeau, I., Moser, A., Hainque, B., Vidaud, M., \& Aubourg, P. (2005). Decreased expression of ABCD4 and BG1 genes early in the pathogenesis of X-linked adrenoleukodystrophy. Human Molecular Genetics, 14, 1293-1303. https://doi. org $/ 10.1093 / \mathrm{hmg} /$ ddi 140

Aubourg, P. (2015). Cerebral adrenoleukodystrophy: A demyelinating disease that leaves the door wide open. Brain, 138, 3133-3136.

Aubourg, P., Adamsbaum, C., Lavallard-Rousseau, M.-C., Rocchiccioli, F., Cartier, N., Jambaque, I., ... Bougneres, P.-F. (1993). A two-year trial of oleic and erucic acids ("Lorenzo's oil") as treatment for adrenomyeloneuropathy. New England Journal of Medicine, 329, 745-752. https://doi.org/10.1056/NEJM199309 093291101

Aubourg, P. R., Sack, G. H., Jr., \& Moser, H. W. (1988). Frequent alterations of visual pigment genes in adrenoleukodystrophy. American Journal of Human Genetics, 42, 408-413.

Berger, J., Forss-Petter, S., \& Eichler, F. S. (2014). Pathophysiology of X-linked adrenoleukodystrophy. Biochimie, 98, 135-142. https:// doi.org/10.1016/j.biochi.2013.11.023

Bezman, L., Moser, A. B., Raymond, G. V., Rinaldo, P., Watkins, P. A., Smith, K. D., ... Moser, H. W. (2001). Adrenoleukodystrophy: Incidence, new mutation rate, and results of extended family screening. Annals of Neurology, 49, 512-517. https://doi.org/10.1002/ ana. 101 
Bizzozero, O. A., Zuniga, G., \& Lees, M. B. (1991). Fatty acid composition of human myelin proteolipid protein in peroxisomal disorders. Journal of Neurochemistry, 56, 872. https://doi. org/10.1111/j.1471-4159.1991.tb02003.x

Blaw, M. E. (1970). Melanodermic type leukodystrophy (adreno-leukodystrophy). In P. J. Vinken \& C. W. Bruyn (Eds.), Handbook of clinical neurology (Vol. 10, pp. 128-133). New York, NY: American Elsevier.

Boehm, C. D., Cutting, G. R., Lachtermacher, M. B., Moser, H. W., \& Chong, S. S. (1999). Accurate DNA-based diagnostic and carrier testing for X-linked adrenoleukodystrophy. Molecular Genetics and Metabolism, 66, 128-136. https://doi.org/10.1006/mgme.1998.2779

Brites, P., Mooyer, P. A., El Mrabet, L., Waterham, H. R., \& Wanders, R. J. (2009). Plasmalogens participate in very-long-chain fatty acid-induced pathology. Brain, 132, 482-492. https://doi.org/10.1093/ brain/awn295

Bryleva, E., Rogers, M. A., Chang, C. C. Y., Buen, F., Harris, B. T., Rousselet, E., ... Chang, T.-Y. (2010). Acat1 gene ablation increases 24(S)-hydroxycholesterol content in the brain and ameliorates amyloid pathology in mice with AD. Proceedings of the National Academy of Sciences, 107, 3081-3086. https://doi.org/10.1073/ pnas.0913828107

Budka, H., Sluga, E., \& Heiss, W. D. (1976). Spastic paraplegia associated with Addison's disease: Adult variant of adreno-leukodystrophy. Journal of Neurology, 213, 237-250. https://doi.org/10.1007/ BF00312873

Burtman, E., \& Regelmann, M. O. (2016). Endocrine dysfunction in $\mathrm{X}$-linked adrenoleukodystrophy. Endocrinology and Metabolism Clinics of North America, 45, 295-309. https://doi.org/10.1016/j. ec1.2016.01.003

Cartier, N., Hacein-Bey-Abina, S., Bartholomae, C. C., Veres, G., Schmidt, M., Kutschera, I., ... Aubourg, P. (2009). Hematopoietic stem cell gene therapy with a lentiviral vector in X-linked adrenoleukodystrophy. Science, 326, 818-823. https://doi.org/10.1126/ science. 1171242

Casasnovas, C., Ruiz, M., Schluter, A., Naudi, A., Fourcade, S., Veciana, M., ... Pujol, A. (2019). Biomarker identification, safety, and efficacy of high-dose antioxidants for adrenomyeloneuropathy: A phase II pilot study. Neurotherapeutics: the Journal of the American Society for Experimental NeuroTherapeutics, 1-16. https://doi. org/10.1007/s13311-019-00735-2. [Epub ahead of print] PubMed PMID: 31077039.

Chu, B. B., Liao, Y. C., Qi, W., Xie, C., Du, X., Wang, J., ... Song, B. L. (2015). Cholesterol transport through lysosome-peroxisome membrane contacts. Cell, 161, 291-306. https://doi.org/10.1016/j. cell.2015.02.019

Di Paola, M., Cocco, T., \& Lorusso, M. (2000). Arachidonic acid causes cytochrome c release from heart mitochondria. Biochemical and Biophysical Research Communications, 277, 128-133. https://doi. org/10.1006/bbrc.2000.3653

Di Rocco, M., Doria-Lamba, L., \& Caruso, U. (2001). Monozygotic twins with X-linked adrenoleukodystrophy and different phenotypes. Annals of Neurology, 50, 424. https://doi.org/10.1002/ana.1220

Dietschy, J. M. (2009). Central nervous system: Cholesterol turnover, brain development and neurodegeneration. Biological Chemistry, 390, 287-293. https://doi.org/10.1515/BC.2009.035

Dietschy, J. M., \& Turley, S. D. (2004). Thematic review series: Brain lipids. Cholesterol metabolism in the central nervous system during early development and in the mature animal. Journal of Lipid Research, 45, 1375-1397.
Diotel, N., Charlier, T. D., d'Hellencourt, C. L., Couret, D., Trudeau, V. L., Nicolau, J. C., ... Pellegrini, E. (2018). Steroid transport, local synthesis, and signaling within the brain: Roles in neurogenesis, neuroprotection and sexual behaviors. Frontiers in Neuroscience, 12(89), 1-27. https://doi.org/10.3389/fnins.2018.00084

Dubey, P., Raymond, G. V., Moser, A. B., Kharkar, S., Bezman, L., \& Moser, H. W. (2005). Adrenal insufficiency in asymptomatic adrenoleukodystrophy patients identified by very long-chain fatty acid screening. Journal of Pediatrics, 146, 528-532. https://doi. org/10.1016/j.jpeds.2004.10.067

Eichler, F., Duncan, C., Musolino, P. L., Orchard, P. J., De Oliveira, S., Thrasher, A. J., ... Williams, D. A. (2017). Hematopoietic stemcell gene therapy for cerebral adrenoleukodystrophy. New England Journal of Medicine, 377, 1630-1638. https://doi.org/10.1056/ NEJMoa1700554

Eichler, F., Mahmood, A., Loes, D., Bezman, L., Lin, D., Moser, H. W., \& Raymond, G. V. (2007). Magnetic resonance imaging detection of lesion progression in adult patients with X-linked adrenoleukodystrophy. Archives of Neurology, 64, 59-664. https://doi.org/10.1001/ archneur.64.5.659

Engelen, M., Barbier, M., Dijkstra, I. M., Schur, R., de Bie, R. M., Verhamme, C., ... Kemp, S. (2014). X-linked adrenoleukodystrophy in women: A cross-sectional cohort study. Brain, 137, 693-706. https://doi.org/10.1093/brain/awt361

Engelen, M., Ofman, R., Dijkgraaf, M. G., Hijzen, M., van der Wardt, L. A., van Geel, B. M., ... Kemp, S. (2010). Lovastatin in X-linked adrenoleukodystrophy. New England Journal of Medicine, 362, 276-277. https://doi.org/10.1056/NEJMc0907735

Engelen, M., Schackmann, M. J., Ofman, R., Sanders, R. J., Dijkstra, I. M., Houten, S. M., ... Kemp, S. (2012a). Bezafibrate lowers very long-chain fatty acids in X-linked adrenoleukodystrophy fibroblasts by inhibiting fatty acid elongation. Journal of Inherited Metabolic Disease, 35, 1137-1145. https://doi.org/10.1007/s1054 5-012-9471-4

Engelen, M., Tran, L., Ofman, R., Brennecke, J., Moser, A. B., Dijkstra, I. M., ... Kemp, S. (2012b). Bezafibrate for X-linked adrenoleukodystrophy. PLoS ONE, 7, e41013. https://doi.org/10.1371/journ al.pone.0041013

Fanconi, A., Prader, A., Isler, W., Luethy, F., \& Siebenmann, R. (1963). Morbus Addison mit Hirnskerose im Kindesalter-Ein hereditäres Syndrome mit X-chromosomaler Vererbung? Helv Paediatr Acta, 18, 480-501.

Farooqui, A. A., Ong, W. Y., \& Horrocks, L. A. (2003). Plasmalogens, docosahexaenoic acid and neurological disorders. Advances in Experimental Medicine and Biology, 544, 335-354.

Fatemi, A., Barker, P. B., Ulug, A. M., Nagae-Poetscher, L. M., Beauchamp, N. J., Moser, A. B., ... Naidu, S. (2003). MRI and proton MRSI in women heterozygous for X-linked adrenoleukodystrophy. Neurology, 60(8), 1301-1307. https://doi.org/10.1212/01. WNL.0000059546.15529.CB

Forss-Petter, S., Werner, H., Berger, J., Lassmann, H., Molzer, B., Schwab, M. H., ... Nave, K. A. (1997). Targeted inactivation of the $\mathrm{X}$-linked adrenoleukodystrophy gene in mice. Journal of Neuroscience Research, 50, 829-843. https://doi. org/10.1002/(SICI)1097-4547(19971201)50:5<829:AID-JNR19 $>3.0 . \mathrm{CO} ; 2-\mathrm{W}$

Fourcade, S., Lopez-Erauskin, J., Galino, J., Duval, C., Naudi, A., Jove, M., ... Pujol, A. (2008). Early oxidative damage underlying neurodegeneration in X-adrenoleukodystrophy. Human Molecular Genetics, 17, 1762-1773. https://doi.org/10.1093/hmg/ddn085 
Fourcade, S., Lopez-Erauskin, J., Ruiz, M., Ferrer, I., \& Pujol, A. (2014). Mitochondrial dysfunction and oxidative damage cooperatively fuel axonal degeneration in X-linked adrenoleukodystrophy. Biochimie, 98, 143-149. https://doi.org/10.1016/j. biochi.2013.09.012

Fourcade, S., Ruiz, M., Guilera, C., Hahnen, E., Brichta, L., Naudi, A., ... Pujol, A. (2010). Valproic acid induces antioxidant effects in X-linked adrenoleukodystrophy. Human Molecular Genetics, 19 , 2005-2014. https://doi.org/10.1093/hmg/ddq082

Golovko, M. Y., \& Murphy, E. J. (2006). Uptake and metabolism of plasma-derived erucic acid by rat brain. Journal of Lipid Research, 47, 1289-1297. https://doi.org/10.1194/j1r.M600029-JLR200

Gong, Y., Mu, D., Prabhakar, S., Moser, A., Musolino, P., Ren, J., ... Eichler, F. S. (2015). Adenoassociated virus serotype 9-mediated gene therapy for X-linked adrenoleukodystrophy. Molecular Therapy, 23, 824-834. https://doi.org/10.1038/mt.2015.6

Gong, Y., Sasidharan, N., Laheji, F., Frosch, M., Musolino, P., Tanzi, R., ... Eichler, F. (2017). Microglial dysfunction as a key pathological change in adrenomyeloneuropathy. Annals of Neurology, 82, 813-827. https://doi.org/10.1002/ana.25085

Gordon, H. B., Valdez, L., \& Letsou, A. (2018). Etiology and treatment of adrenoleukodystrophy: New insights from Drosophila. Dis Model Mech, 11. https://doi.org/10.1242/dmm.031286. [PubMed: 29739804].

Griffin, J. W., Goren, E., Schaumburg, H., Engel, W. K., \& Loriaux, L. (1977). Adrenomyeloneuropathy: A probable variant of adrenoleukodystrophy. I. Clinical and Endocrinologic Aspects. Neurology, 27, 1107-1113. https://doi.org/10.1212/WNL.27.12.1107

Haberfeld, W., \& Spieler, F. (1910). Zur diffusen HirnRückenmarksklerose im Kindesalter. Deutsche Zeitschrift Für Nervenheilkunde, 40(5-6), 436-463. https://doi.org/10.1007/BF016 29013

Halliwell, B., \& Gutteridge, J. M. C. (2015). Free radicals in biology and medicine (5th ed.). Oxford, UK: Oxford University Press.

Hartley, M. D., Kirkemo, L. L., Banerji, T., \& Scanlan, T. S. (2017). A thyroid hormone-based strategy for correcting the biochemical abnormality in X-linked adrenoleukodystrophy. Endocrinology, 158, 1328-1338. https://doi.org/10.1210/en.2016-1842

Hayashi, H., \& Oohashi, M. (1995). Incorporation of acetyl-CoA generated from peroxisomal beta-oxidation into ethanolamine plasmalogen of rat liver. Biochimica Et Biophysica Acta, 1254, 319-325.

Haynes, C. A., \& De Jesus, V. R. (2012). Improved analysis of C26:0lysophosphatidylcholine in dried-blood spots via negative ion mode HPLC-ESI-MS/MS for X-linked adrenoleukodystrophy newborn screening. Clinica Chimica Acta, 413, 1217-1221. https://doi. org/10.1016/j.cca.2012.03.026

Hein, S., Schonfeld, P., Kahlert, S., \& Reiser, G. (2008). Toxic effects of X-linked adrenoleukodystrophy-associated, very long chain fatty acids on glial cells and neurons from rat hippocampus in culture. Human Molecular Genetics, 17, 1750-1761. https://doi. org/10.1093/hmg/ddn066

Hershkovitz, E., Narkis, G., Shorer, Z., Moser, A. B., Watkins, P. A., Moser, H. W., \& Manor, E. (2002). Cerebral X-linked adrenoleukodystrophy in a girl with Xq27-Ter deletion. Annals of Neurology, 52, 234-237. https://doi.org/10.1002/ana.10248

Ho, J. K., Moser, H., Kishimoto, Y., \& Hamilton, J. A. (1995). Interactions of a very long chain fatty acid with model membranes and serum albumin. Implications for the pathogenesis of adrenoleukodystrophy. Journal of Clinical Investigation, 96, 1455-1463. https ://doi.org/10.1172/JCI118182
Hu, A., Zhao, X.-T., Tu, H., Xiao, T., Fu, T., Wang, Y., ... Song, B.L. (2018). PIP4K2A regulates intracellular cholesterol transport through modulating $\mathrm{PI}(4,5) \mathrm{P}_{2}$ homeostasis. Journal of Lipid Research, 59, 507-514.

Hubbard, W. C., Moser, A. B., Liu, A. C., Jones, R. O., Steinberg, S. J., Lorey, F., ... Raymond, G. V. (2009). Newborn screening for $\mathrm{X}$-linked adrenoleukodystrophy (X-ALD): Validation of a combined liquid chromatography-tandem mass spectrometric (LC-MS/MS) method. Molecular Genetics and Metabolism, 97, 212-220. https:// doi.org/10.1016/j.ymgme.2009.03.010

Hubbard, W. C., Moser, A. B., Tortorelli, S., Liu, A., Jones, D., \& Moser, H. (2006). Combined liquid chromatography-tandem mass spectrometry as an analytical method for high throughput screening for X-linked adrenoleukodystrophy and other peroxisomal disorders: Preliminary findings. Molecular Genetics and Metabolism, 89, 185-187. https://doi.org/10.1016/j.ymgme.2006.05.001

Huffnagel, I. C., Dijkgraaf, M. G. W., Janssens, G. E., van Weeghel, M., van Geel, B. M., Poll-The, B. T., ... Engelen, M. (2019a). Disease progression in women with X-linked adrenoleukodystrophy is slow. Orphanet Journal of Rare Diseases, 14, 30. https://doi.org/10.1186/ s13023-019-1008-6

Huffnagel, I. C., Laheji, F. K., Aziz-Bose, R., Tritos, N. A., Marino, R., Linthorst, G. E., ... Eichler, F. (2019b). The natural history of adrenal insufficiency in X-linked adrenoleukodystrophy: An international collaboration. Journal of Clinical Endocrinology and Metabolism, 104, 118-126. https://doi.org/10.1210/jc.2018-01307

Huffnagel, I. C., van Ballegoij, W. J. C., van Geel, B. M., Vos, J., Kemp, S., \& Engelen, M. (2019c). Progression of myelopathy in males with adrenoleukodystrophy: Towards clinical trial readiness. Brain, 142, 334-343.

Huffnagel, I. C., van de Beek, M. C., Showers, A. L., Orsini, J. J., Klower, F. C. C., Dijkstra, I. M. E., ..., Kemp, S. (2017). Comparison of C26:0-carnitine and C26:0-lysophosphatidylcholine as diagnostic markers in dried blood spots from newborn and patients with adrenoleukodystrophy. Molecular Genetics and Metabolism, 122, 209-215.

Igarashi, M., Belchis, D., \& Suzuki, K. (1976b). Brain gangliosides in adrenoleukodystrophy. Journal of Neurochemistry, 27, 327-328. https://doi.org/10.1111/j.1471-4159.1976.tb01593.x

Igarashi, M., Schaumburg, H. H., Powers, J., Kishmoto, Y., Kolodny, E., \& Suzuki, K. (1976a). Fatty acid abnormality in adrenoleukodystrophy. Journal of Neurochemistry, 26, 851-860. https://doi. org/10.1111/j.1471-4159.1976.tb04462.x

Islinger, M., Voelkl, A., Fahimi, H. D., \& Schrader, M. (2018). The peroxisome: An update on mysteries 2.0. Histochemistry and Cell Biology, 150, 443-471. https://doi.org/10.1007/s0041 8-018-1722-5

Jakobsson, A., Westerberg, R., \& Jacobsson, A. (2006). Fatty acid elongases in mammals: Their regulation and roles in metabolism. Progress in Lipid Research, 45, 237-249. https://doi.org/10.1016/j. plipres.2006.01.004

Jang, J., Lee, J. W., Song, J., Kim, D. W., \& Min, K. H. (2019). Exogenous addition of 25-hydroxycholesterol reduces level of very long-chain fatty acids in X-linked adrenoleukodystrophy. ChemistryOpen, 8, 188-191. https://doi.org/10.1002/open.201800281

Jang, J., Park, S., Jin Hur, H., Cho, H. J., Hwang, I., Pyo Kang, Y., ... Kim, D. W. (2016). 25-hydroxycholesterol contributes to cerebral inflammation of X-linked adrenoleukodystrophy through activation of the NLRP3 inflammasome. Nature Communications, 7, 13129. https://doi.org/10.1038/ncomms13129 
Jarc, E., Kump, A., Malavasic, P., Eichmann, T. O., Zimmermann, R., \& Petan, T. (2018). Lipid droplets induced by secreted phospholipase A2 and unsaturated fatty acids protect breast cancer cells from nutrient and lipotoxic stress. Biochimica Et Biophysica Acta (BBA)Molecular and Cell Biology of Lipids, 1863, 247-265. https://doi. org/10.1016/j.bbalip.2017.12.006

Jin, Y., Strunk, B. S., \& Weisman, L. S. (2015). Close encounters of the lysosome/peroxisome kind. Cell, 161(2), 197-198. https://doi. org/10.1016/j.cell.2015.03.046

Johnson, A. B., Schaumburg, H. H., \& Powers, J. M. (1976). Histochemical characteristics of the striated inclusions of adrenoleukodystrophy. Journal of Histochemistry and Cytochemistry, 24, 725-730. https://doi.org/10.1177/24.6.59773

Kannan, S., Dai, H., Navath, R. S., Balakrishnan, B., Jyoti, A., Janisse, J., ... Kannan, R. M. (2012). Dendrimer-based postnatal therapy for neuroinflammation and cerebral palsy in a rabbit model. Science Translational Medicine, 4, 130ra46-130ra46. https://doi. org/10.1126/scitranslmed.3003162

Karten, B., Campenot, R. B., Vance, D. E., \& Vance, J. E. (2006). Expression of ABCG1, but not ABCA1, correlates with choelsterol release by astroglia. Journal of Biological Chemistry, 281, 4049-4057.

Kassmann, C. M., Lappe-Siefke, C., Baes, M., Brügger, B., Mildner, A., Werner, H. B., ... Nave, K.-A. (2007). Axonal loss and neuroinflammation caused by peroxisome-deficient oligodendrocytes. Nature Genetics, 8, 969-976. https://doi.org/10.1038/ng2070

Kemp, S., Berger, J., \& Aubourg, P. (2012). X-linked adrenoleukodystrophy: Clinical, metabolic, genetic and pathophysiological aspects. Biochimica Et Biophysica Acta, 1822, 1465-1474. https://doi. org/10.1016/j.bbadis.2012.03.012

Kemp, S., Huffnagel, I. C., Linthorst, G. E., Wanders, R. J., \& Engelen, M. (2016). Adrenoleukodystrophy-neuroendocrine pathogenesis and redefinition of natural history. Nature Reviews Endocrinology, 12, 606-615. https://doi.org/10.1038/nrendo.2016.90

Kemp, S., Pujol, A., Waterham, H. R., van Geel, B. M., Boehm, C. D., Raymond, G. V., ... Moser, H. W. (2001). ABCD1 mutations and the X-linked adrenoleukodystrophy mutation database: Role in diagnosis and clinical correlations. Human Mutation, 18, 499-515. https://doi.org/10.1002/humu.1227

Kemp, S., Theodoulou, F. L., \& Wanders, R. J. (2011). Mammalian peroxisomal ABC transporters: From endogenous substrates to pathology and clinical significance. British Journal of Pharmacology, 164, 1753-1766. https://doi.org/10.1111/j.1476-5381.2011.01435.x

Kemp, S., \& Wanders, R. (2010). Biochemical aspects of X-linked adrenoleukodystrophy. Brain Pathology, 20, 831-837. https://doi. org/10.1111/j.1750-3639.2010.00391.x

Kemp, S., Wei, H. M., Lu, J. F., Braiterman, L. T., McGuinness, M. C., Moser, A. B., ... Smith, K. D. (1998). Gene redundancy and pharmacological gene therapy: Implications for X-linked adrenoleukodystrophy. Nature Medicine, 4, 1261-1268. https://doi. org/10.1038/3242

Kemper, A. R., Brosco, J., Comeau, A. M., Green, N. S., Grosse, S. D., Jones, E., ... Tanksley, S. (2017). Newborn screening for X-linked adrenoleukodystrophy: Evidence summary and advisory committee recommendation. Genetics in Medicine, 19, 121-126. https://doi. org/10.1038/gim.2016.68

Khan, M., Singh, J., \& Singh, I. (2008). Plasmalogen deficiency in cerebral adrenoleukodystrophy and its modulation by lovastatin. Journal of Neurochemistry, 106, 1766-1779. https://doi. org/10.1111/j.1471-4159.2008.05513.x
Kishimoto, Y., Moser, H. W., \& Suzuki, K. (1984). Neurochemistry of adrenoleukodystophy. In A. E. Lajtha (Ed.). The handbook of neurochemistry (Vol. 10, p. 125). New York, NY: Plenum.

Kleinecke, S., Richert, S., Hoz, L., Brugger, B., Kungl, T., Asadollahi, E., .. Naseri, K. (2017). Peroxisomal Dysfunctions Cause Lysosomal Storage and Axonal Kv1 Channel Redistribution in Periferal Neuropathy. Elife, 6, 1-17.

Kobayashi, T., Shinnoh, N., Kondo, A., \& Yamada, T. (1997). Adrenoleukodystrophy protein-deficient mice represent abnormality of very long chain fatty acid metabolism. Biochemical and Biophysical Research Communications, 232, 631-636. https://doi. org/10.1006/bbrc.1997.6340

Koerte, I. K., Lin, A. P., Willems, A., Muehlmann, M., Hufschmidt, J., Coleman, M. J., ... Shenton, M. E. (2015). A review of neuroimaging findings in repetitive brain trauma. Brain Pathology, 25, 318-349. https://doi.org/10.1111/bpa.12249

Korenke, G. C., Fuchs, S., Krasemann, E., Doerr, H. G., Wilichowski, E., Hunneman, D. H., \& Hanefeld, F. (1996). Cerebral adrenoleukodystrophy (ALD) in only one of monozygotic twins with an identical ALD genotype. Annals of Neurology, 40, 254-257. https://doi. org/10.1002/ana.410400221

Korge, P., Honda, H. M., \& Weiss, J. N. (2003). Effects of fatty acids in isolated mitochondria: Implications for ischemic injury and cardioprotection. American Journal of Physiology. Heart and Circulatory Physiology, 285, H259-269. https://doi.org/10.1152/ ajpheart.01028.2002

Kruska, N., Schonfeld, P., Pujol, A., \& Reiser, G. (2015). Astrocytes and mitochondria from adrenoleukodystrophy protein (ABCD1)deficient mice reveal that the adrenoleukodystrophy-associated very long-chain fatty acids target several cellular energy-dependent functions. Biochimica Et Biophysica Acta, 1852, 925-936. https://doi. org/10.1016/j.bbadis.2015.01.005

Lauer, A., Da, X., Hansen, M. B., Boulouis, G., Ou, Y., Cai, X., ... Musolino, P. L. (2017). ABCD1 dysfunction alters white matter microvascular perfusion. Brain, 140, 3139-3152. https://doi. org/10.1093/brain/awx262

Launay, N., Ruiz, M., Grau, L., Ortega, F. J., Ilieva, E. V., Martinéz, J. J., ... Fourcade, S. (2017). Tauroursodeoxycholic bile acid arrests axonal degeneration by inhibiting the unfolded protein response in X-linked adrnoleukodystrophy. Acta Neuropathologica, 133, 283-301.

Lee, D. K., Long, N. P., Jung, J., Kim, T. J., Na, E., Kang, Y. P., ... Jang, J. (2019). Integrative lipidomic and transcriptomic analysis of X-linked adrenoleukodystrophy reveals distinct lipidome signatures between adrenomyeloneuropathy and childhood cerebral adrenoleukodystrophy. Biochemical and Biophysical Research Communications, 508, 563-569. https://doi.org/10.1016/j. bbrc.2018.11.123

Li, N., Sancak, Y., Frasor, J., \& Atilla-Gokcumen, G. E. (2018). A protective role for triacylglycerols during apoptosis. Biochemistry, 57, 72-80. https://doi.org/10.1021/acs.biochem.7b00975

Liberato, A. P., Mallack, E. J., Aziz-Bose, R., Hayden, D., Lauer, A., Caruso, P. A., ... Eichler, F. S. (2019). MRI brain lesions in asymptomatic boys with X-linked adrenoleukodystrophy. Neurology, 92, e1698. https://doi.org/10.1212/WNL.0000000000007294

Listenberger, L. L., Han, X., Lewis, S. E., Cases, S., Farese, R. V., Jr., Ory, D. S., \& Schaffer, J. E. (2003). Triglyceride accumulation protects against fatty acid-induced lipotoxicity. Proceedings of the National Academy of Sciences, 100, 3077-3082. https://doi. org/10.1073/pnas.0630588100 
Loes, D. J., Fatemi, A., Melhem, E. R., Gupte, N., Bezman, L., Moser, H. W., \& Raymond, G. V. (2003). Analysis of MRI patterns aids prediction of progression in X-linked adrenoleukodystrophy. Neurology, 61, 369-374. https://doi.org/10.1212/01.WNL.00000 79050.91337 .83

Lopez-Erauskin, J., Fourcade, S., Galino, J., Ruiz, M., Schluter, A., Naudi, A., ... Pujol, A. (2011). Antioxidants halt axonal degeneration in a mouse model of X-adrenoleukodystrophy. Annals of Neurology, 70, 84-92. https://doi.org/10.1002/ana.22363

Lu, J. F., Lawler, A. M., Watkins, P. A., Powers, J. M., Moser, A. B., Moser, H. W., \& Smith, K. D. (1997). A mouse model for X-linked adrenoleukodystrophy. Proceedings of the National Academy of Sciences, 94, 9366-9371. https://doi.org/10.1073/pnas.94.17.9366

Luo, J., Jiang, L.-Y., Yang, H., \& Song, B.-L. (2018). Intracellular cholesterol transport by sterol transfer proteins at membrane contact sites. Trends in Biochemical Sciences, 44, 273-293. https://doi. org/10.1016/j.tibs.2018.10.001

Luo, J., Liao, Y.-C., Xiao, J., \& Song, B.-L. (2017). Measurement of cholesterol transfer from lysosome to peroxisome using an in vitro reconstitution assay, Chapter 11. In I. C. Gelissen \& A. J. Brown (Eds.), Cholesterol homeostasis: Methods and protocols, methods in molecular biology (Vol. 1583, pp. 141-161). New York, NY: Springer Science+Business Media LLC. https://doi. org/10.1007/978-1-4939-6875-6_11

Lütjohann, D., Breuer, O., Ahlborg, G., Nennesmo, I., Siden, A., Diczfalusy, U., \& Bjorkhem, I. (1996). Cholesterol homeostasis in human brain: Evidence for an age-dependent flux of 24S-hydroxycholesterol from the brain into the circulation. Proceedings of the National Academy of Sciences, 93, 9799-9804. https://doi.org/10.1073/pnas.93.18.9799

Mahmood, A., Raymond, G. V., Dubey, P., Peters, C., \& Moser, H. W. (2007). Survival analysis of haematopoietic cell transplantation for childhood cerebral X-linked adrenoleukodystrophy: A comparison study. The Lancet Neurology, 6, 687-692. https://doi.org/10.1016/ S1474-4422(07)70177-1

Maier, E. M., Kammerer, S., Muntau, A. C., Wichers, M., Braun, A., \& Roscher, A. A. (2002). Symptoms in carriers of adrenoleukodystrophy relate to skewed X inactivation. Annals of Neurology, 52, 683-688. https://doi.org/10.1002/ana.10376

Maly, D. J., \& Papa, F. R. (2014). Druggable sensors of the unfolded protein response. Nature Chemical Biology, 10, 892-901. https:// doi.org/10.1038/nchembio.1664

Marchetti, D. P., Donida, B., da Rosa, H. T., Manini, P. R., Moura, D. J., Saffi, J., ... Vargas, C. R. (2015). Protective effect of antioxidants on DNA damage in leukocytes from X-linked adrenoleukodystrophy patients. International Journal of Developmental Neuroscience, 43, 8-15. https://doi.org/10.1016/j.ijdevneu.2015.03.004

Marchetti, D. P., Steffens, L., Jacques, C. E., Guerreiro, G. B., Mescka, C. P., Deon, M., ... Vargas, C. R. (2018). Oxidative imbalance, nitrative stress, and inflammation in $\mathrm{C} 6$ glial cells exposed to hexacosanoic acid: Protective effect of $\mathrm{N}$-acetyl-L-cysteine, trolox, and rosuvastatin. Cellular and Molecular Neurobiology, 38, 1505-1516. https://doi.org/10.1007/s10571-018-0626-1

Matsukawa, T., Asheuer, M., Takahashi, Y., Goto, J., Suzuki, Y., Shimozawa, N., ... Tsuji, S. (2011). Idebtification of novel SNPs of $A B C D 1, A B C D 2, A B C D 3$, and $A B C D 4$ genes in patients with $\mathrm{X}$-linked adrenoleukodystrophy (ALD) based on comprehensive resequencing and associated studies with ALD phenotypes. Neurogenetics, 12, 41-50.
McAllister, T. (2014). Task-related Cerebral activation pre and post season in a cohort of collegiate contact sport athletes brain injury, International Brain Injury Association Conference; Abstract.

McDonald, J. G., \& Russell, D. W. (2010). Editorial: 25-hydroxycholesterol: A new life in immunology. Journal of Leukocyte Biology, 88, 1071-1072. https://doi.org/10.1189/jlb.0710418

McMillan, M., \& DeMorrow, S. (2016). Effects of bile acids on neurological function and disease. The FASEB Journal, 11, 3658-3668. https://doi.org/10.1096/fj.201600275R

Migeon, B. R., Moser, H. W., Moser, A. B., Axelman, J., Sillence, D., \& Norum, R. A. (1981). Adrenoleukodystrophy: Evidence for X linkage, inactivation, and selection favoring the mutant allele in heterozygous cells. Proceedings of the National Academy of Sciences, 78, 5066-5070. https://doi.org/10.1073/pnas.78.8.5066

Miller, W. P., Rothman, S. M., Nascene, D., Kivisto, T., DeFor, T. E., Ziegler, R. S., ... Orchard, P. J. (2011). Outcomes after allogeneic hematopoietic cell transplantation for childhood cerebral adrenoleukodystrophy: The largest single-institution cohort report. Blood, 118, 1971-1978. https://doi.org/10.1182/blood-2011-01-329235

Morato, L., Galino, J., Ruiz, M., Calingasan, N. Y., Starkov, A. A., Dumont, M., ... Pujol, A. (2013). Pioglitazone halts axonal degeneration in a mouse model of X-linked adrenoleukodystrophy. Brain, 136, 2432-2443. https://doi.org/10.1093/brain/awt143

Moser, A., Jones, R., Hubbard, W., Tortorelli, S., Orsini, J., Caggana, M., ... Raymond, G. (2016). Newborn screening for X-linked adrenoleukodystrophy. International Journal of Neonatal Screening, 2, 1-5. https://doi.org/10.3390/ijns2040015

Moser, A. B., Kreiter, N., Bezman, L., Lu, S., Raymond, G. V., Naidu, S., \& Moser, H. W. (1999). Plasma very long chain fatty acids in 3,000 peroxisome disease patients and 29,000 controls. Annals of Neurology, 45, 100-110. https://doi.org/10.1002/1531-8249(19990 1) 45:1<100:AID-ART16>3.0.CO;2-U

Moser, H. W. (2006). Watch out for diagnostic "junk". Journal of Inherited Metabolic Disease, 29, 550.

Moser, H. W., Loes, D. J., Melhem, E. R., Raymond, G. V., Bezman, L., Cox, C. S., \& Lu, S. E. (2000). X-Linked adrenoleukodystrophy: Overview and prognosis as a function of age and brain magnetic resonance imaging abnormality. A study involving 372 patients. Neuropediatrics, 31, 227-239. https://doi.org/10.1055/s-2000-9236

Moser, H. W., Moser, A. B., Frayer, K. K., Chen, W., Schulman, J. D., O'Neill, B. P., \& Kishimoto, Y. (1981). Adrenoleukodystrophy: Increased plasma content of saturated very long chain fatty acids. Neurology, 31, 1241-1249. https://doi.org/10.1212/ WNL.31.10.1241

Moser, H. W., Moser, A. B., Kawamura, N., Murphy, J., Suzuki, K., Schaumburg, H., \& Kishimoto, Y. (1980). Adrenoleukodystrophy: Elevated C26 fatty acid in cultured skin fibroblasts. Annals of Neurology, 7, 542-549. https://doi.org/10.1002/ana.410070607

Moser, H. W., Moser, A. B., Powers, J. M., Nitowsky, H. M., Schaumburg, H. H., Norum, R. A., \& Migeon, B. R. (1982). The prenatal diagnosis of adrenoleukodystrophy. Demonstration of increased hexacosanoic acid levels in cultured amniocytes and fetal adrenal gland. Pediatric Research, 16, 172-175. https://doi.org/10.1203/00006 450-198203000-00002

Moser, H. W., Raymond, G. V., Lu, S. E., Muenz, L. R., Moser, A. B., Xu, J., ... Odone, A. (2005). Follow-up of 89 asymptomatic patients with adrenoleukodystrophy treated with Lorenzo's oil. Archives of Neurology, 62, 1073-1080. https://doi.org/10.1001/ archneur.62.7.1073 
Moser, H. W., Smith, K. D., Watkins, P. A., Powers, J., \& Moser, A B. (2001). X-linked adrenoleukodystrophy. In C. R. Scriver, A. L. Beaudet, W. S. Sly, \& D. Valle (Eds.), The metabolic and molecular basis of inherited disease (8th ed., pp. 3257-3301). New York, NY: McGraw-Hill Book Co.

Mosser, J., Douar, A. M., Sarde, C. O., Kioschis, P., Feil, R., Moser, H., ... Aubourg, P. (1993). Putative X-linked adrenoleukodystrophy gene shares unexpected homology with $\mathrm{ABC}$ transporters. Nature, 361, 726-730. https://doi.org/10.1038/361726a0

Musolino, P. L., Gong, Y., Snyder, J. M., Jimenez, S., Lok, J., Lo, E. H., ... Eichler, F. S. (2015). Brain endothelial dysfunction in cerebral adrenoleukodystrophy. Brain, 138, 3206-3220. https://doi. org/10.1093/brain/awv250

Musolino, P. L., Rapalino, O., Caruso, P., Caviness, V. S., \& Eichler, F. S. (2012). Hypoperfusion predicts lesion progression in cerebral X-linked adrenoleukodystrophy. Brain, 135, 2676-2683. https://doi. org/10.1093/brain/aws206

Nury, T., Zarrouk, A., Ragot, K., Debbabi, M., Riedinger, J. M., Vejux, A., ... Lizard, G. (2017). 7-Ketocholesterol is increased in the plasma of X-ALD patients and induces peroxisomal modifications in microglial cells: Potential roles of 7-ketocholesterol in the pathophysiology of X-ALD. Journal of Steroid Biochemistry and Molecular Biology, 169, 123-136. https://doi.org/10.1016/j. jsbmb.2016.03.037

Ofman, R., Dijkstra, I. M., van Roermund, C. W., Burger, N., Turkenburg, M., van Cruchten, A., ... Kemp, S. (2010). The role of ELOVL1 in very long-chain fatty acid homeostasis and X-linked adrenoleukodystrophy. EMBO Molecular Medicine, 2, 90-97. https ://doi.org/10.1002/emmm.201000061

Ogino, T., \& Suzuki, K. (1981). Specificities of human and rat brain enzymes of cholesterol ester metabolism toward very long chain fatty acids: Implication for biochemical pathogenesis of adrenoleukodystrophy. Journal of Neurochemistry, 36, 776-779. https://doi. org/10.1111/j.1471-4159.1981.tb01657.x

Ohno, Y., Suto, S., Yamanaka, M., Mizutani, Y., Mitsutake, S., Igarashi, Y., ... Kihara, A. (2010). ELOVL1 production of C24 acyl-CoAs is linked to sphingolipid synthesis. Proceedings of the National Academy of Sciences, 107(43), 18439-18444. PMC 2932002.

Parisi, L. R., Li, N., \& Atilla-Gokcumen, G. E. (2017). Very long chain fatty acids are functionally involved in necroptosis. Cell Chemical Biology, 24(12), 1445-1454.e8. https://doi.org/10.1016/j.chemb iol.2017.08.026

Peters, C., Charnas, L. R., Tan, Y., Ziegler, R. S., Shapiro, E. G., DeFor, T., ... Krivit, W. (2004). Cerebral X-linked adrenoleukodystrophy: The international hematopoietic cell transplantation experience from 1982 to 1999. Blood, 104, 881-888. https://doi.org/10.1182/ blood-2003-10-3402

Petrov, A. M., Kasimov, M. R., \& Zefirov, A. L. (2016). Brain cholesterol metabolism and its defects: Linkage to neurodegenerative diseases and synaptic dysfunction. Acta Naturae, 8, 58-73. https:// doi.org/10.32607/20758251-2016-8-1-58-73

Pfrieger, F. W., \& Ungerer, N. (2011). Cholesterol metabolism in neurons and astrocytes. Progress in Lipid Research, 50, 357-371. https ://doi.org/10.1016/j.plipres.2011.06.002

Poulos, A., Gibson, R., Sharp, P., Beckman, K., \& Grattan-Smith, P. (1994). Very long chain fatty acids in X-linked adrenoleukodystrophy brain after treatment with Lorenzo's oil. Annals of Neurology, 36, 741-746. https://doi.org/10.1002/ana.410360509
Powers, J. M. (1985). Adreno-leukodystrophy (adreno-testiculo-leukomyelo-neuropathic-complex). Clinical Neuropathology, 4, 181-199.

Powers, J. M. (2005). Adreno-leukodystrophy: A personal historical note. Acta Neuropathologica, 109, 124-127. https://doi.org/10.1007/ s00401-004-0961-9

Powers, J. M., DeCiero, D. P., Cox, C., Richfield, E. K., Ito, M., Moser, A. B., \& Moser, H. W. (2001). The dorsal root ganglia in adrenomyeloneuropathy: Neuronal atrophy and abnormal mitochondria. Journal of Neuropathology and Experimental Neurology, 60, 493501. https://doi.org/10.1093/jnen/60.5.493

Powers, J. M., DeCiero, D. P., Ito, M., Moser, A. B., \& Moser, H. W. (2000). Adrenomyeloneuropathy: A neuropathologic review featuring its noninflammatory myelopathy. Journal of Neuropathology and Experimental Neurology, 59, 89-102. https://doi.org/10.1093/ jnen/59.2.89

Powers, J. M., Liu, Y., Moser, A. B., \& Moser, H. W. (1992). The inflammatory myelinopathy of adreno-leukodystrophy: Cells, effector molecules, and pathogenetic implications. Journal of Neuropathology and Experimental Neurology, 51, 630-643. https:// doi.org/10.1097/00005072-199211000-00007

Powers, J. M., \& Schaumberg, H. H. (1974a). Adreno-leukodystrophy. Similar ultrastructural changes in adrenal cortical and Schwann cells. Archives of Neurology, 30, 406-408. https://doi.org/10.1001/ archneur.1974.00490350064011

Powers, J. M., \& Schaumburg, H. H. (1973). The adrenal cortex in adreno-leukodystrophy. Archives of Pathology, 96, 305-310.

Powers, J. M., \& Schaumburg, H. H. (1974b). Adreno-leukodystrophy (sex-linked Schilder's disease). A pathogenetic hypothesis based on ultrastructural lesions in adrenal cortex, peripheral nerve and testis. American Journal of Pathology, 76, 481-491.

Powers, J. M., \& Schaumburg, H. H. (1981). The testis in adreno-leukodystrophy. American Journal of Pathology, 102, 90-98.

Powers, J. M., Schaumburg, H. H., Johnson, A. B., \& Raine, C. S. (1980). A correlative study of the adrenal cortex in adreno-leukodystrophy-evidence for a fatal intoxication with very long chain saturated fatty acids. Investigative \& Cell Pathology, 3, 353-376.

Pujol, A., Ferrer, I., Camps, C., Metzger, E., Hindelang, C., Callizot, N., ... Mandel, J. L. (2004). Functional overlap between ABCD1 (ALD) and ABCD2 (ALDR) transporters: A therapeutic target for X-adrenoleukodystrophy. Human Molecular Genetics, 13, 29973006. https://doi.org/10.1093/hmg/ddh323

Pujol, A., Hindelang, C., Callizot, N., Bartsch, U., Schachner, M., \& Mandel, J. L. (2002). Late onset neurological phenotype of the $\mathrm{X}$-ALD gene inactivation in mice: A mouse model for adrenomyeloneuropathy. Human Molecular Genetics, 11, 499-505. https://doi. org/10.1093/hmg/11.5.499

Raas, Q., Gondcaille, C., Hamon, Y., Leoni, V., Caccia, C., Menetrier, F., ... Savary, S. (2019). CRISPR/Cas9-mediated knockout of Abcd 1 and Abcd2 genes in BV-2 cells: Novel microglial models for X-linked Adrenoleukodystrophy. Biochimica Et Biophysica Acta (BBA)_Molecular and Cell Biology of Lipids, 1864, 704-714. https ://doi.org/10.1016/j.bbalip.2019.02.006

Ramsey, R. B., \& Davison, A. N. (1974). Steryl esters and their relationship to normal and diseased human central nervous system. Journal of Lipid Research, 15, 249.

Rasmussen, M., Moser, A. B., Borel, J., Khangoora, S., \& Moser, H. W. (1994). Brain, liver, and adipose tissue erucic and very long chain fatty acid levels in adrenoleukodystrophy patients treated with glyceryl trierucate and trioleate oils (Lorenzo's oil). 
Neurochemical Research, 19, 1073-1082. https://doi.org/10.1007/ BF00968719

Raymond, G. V., Aubourg, P., Paker, A., Escolar, M., Fischer, A., Blanche, S., ... Lund, T. (2019). Survival and functional outcomes in boys with cerebral adrenoleukodystrophy with and without hematopoietic stem cell transplantation. Biology of Blood and Marrow Transplantation, 25, 538-548. https://doi.org/10.1016/j. bbmt.2018.09.036

Raymond, G. V., Jones, R. O., \& Moser, A. B. (2007). Newborn screening for adrenoleukodystrophy: Implications for therapy. Molecular Diagnosis \& Therapy, 11, 381-384. https://doi.org/10.1007/BF032 56261

Raymond, G. V., Moser, A. B., \& Fatemi, A. (2018). X-linked adrenoleukodystrophy (1999, updated 15 Feb 2018). In M. P. Adam, H. H. Ardinger, \& R. A. Pagon (Eds.), Gene reviews [Internet]. Seattle, WA: University of Washington.

Raymond, G. V., Seidman, R., Monteith, T. S., Kolodny, E., Sathe, S., Mahmood, A., \& Powers, J. M. (2010). Head trauma can initiate the onset of adreno-leukodystrophy. Journal of the Neurological Sciences, 290, 70-74. https://doi.org/10.1016/j.jns.2009.11.005

Regelmann, M. O., Kamboj, M. K., Miller, B. S., Nakamoto, J. M., Sarafoglou, K., Shah, S., ... Marino, R. (2018). Adrenoleukodystrophy: Guidance for adrenal surveillance in males identified by newborn screen. Journal of Clinical Endocrinology and Metabolism, 103, 4324-4331. https://doi.org/10.1210/jc.2018-00920

Reinecke, C. J., Knoll, D. P., Pretorius, P. J., Steyn, H. S., \& Simpson, R. H. W. (1985). The correlation between biochemical and histopathological findings in adrenoleukodystrophy. Journal of the Neurological Sciences, 70, 21-38.

Reiser, G., Schonfeld, P., \& Kahlert, S. (2006). Mechanism of toxicity of the branched-chain fatty acid phytanic acid, a marker of Refsum disease, in astrocytes involves mitochondrial impairment. International Journal of Developmental Neuroscience, 24, 113-122. https://doi. org/10.1016/j.ijdevneu.2005.11.002

Rizzo, W. B. (1993). Lorenzo's oil-hope and disappointment. New England Journal of Medicine, 329, 801-802. https://doi. org/10.1056/NEJM199309093291110

Saeed, A. A., Genove, G., Li, T., Lutjohann, D., Olin, M., Mast, N., ... Bjorkhem, I. (2014). Effects of a disrupted blood-brain barrier on cholesterol homeostasis in the brain. Journal of Biological Chemistry, 289, 23712-23722. https://doi.org/10.1074/jbc. M114.556159

Sassa, T., Wakashima, T., Ohno, Y., \& Kihara, A. (2014). Lorenzo's oil inhibits ELOVL1 and lowers the level of sphingomyelin with a saturated very long-chain fatty acid. Journal of Lipid Research, 55, 524-530. https://doi.org/10.1194/jlr.M044586

Schaumburg, H. H., Powers, J. M., Raine, C. S., Suzuki, K., \& Richardson, E. P., Jr. (1975). Adrenoleukodystrophy. A clinical and pathological study of 17 cases. Archives of Neurology, 32, 577-591. https://doi.org/10.1001/archneur.1975.0049051003 3001

Schaumburg, H. H., Powers, J. M., Suzuki, K., \& Raine, C. S. (1974). Adreno-leukodystrophy (sex-linked Schilder disease). Ultrastructural demonstration of specific cytoplasmic inclusions in the central nervous system. Archives of Neurology, 31, 210-213. https://doi.org/10.1001/archneur.1974.00490390092013

Schilder, P. F. (1912). Zur Kenntnis der sogenannten diffusen Sklerose (über Encephalitis periaxialis diffusa). Zeitschrift Für Die Gesamte Neurologie Und Psychiatrie, 10, 1-60. https://doi.org/10.1007/ BF02901445
Schilder, P. F. (1913). Zur Frage der Encephalitis periaxiallis diffusa (sogenannte diffuse Sklerose). Zeitschrift Für Die Gesamte Neurologie Und Psychiatrie, 15, 359-376.

Schilder, P. F. (1924). Die Encephalitis periaxiallis diffusa (nebst Bemerkungen über die Apraxie des Lidschlusses). Archives of Psychiatric, 71, 327-356

Schrifl, U. (2016). Preclinical testing of new therapeutic approaches in $X-A L D$ (Doctoral thesis). University of Vienna, Vienna, Austria.

Shah, N., \& Singh, I. (2017). MicroRNA profiling identifies miR-196a as differentially expressed in childhood adrenoleukodystrophy and adult adrenomyeloneuropathy. Molecular Neurobiology, 54, 13921403. https://doi.org/10.1007/s12035-016-9746-0

Sharp, P., Johnson, D., \& Poulos, A. (1991). Molecular species of phosphatidylcholine containing very long chain fatty acids in human brain: Enrichment in X-linked adrenoleukodystrophy brain and diseases of peroxisome biogenesis brain. Journal of Neurochemistry, 56, 30-37. https://doi.org/10.1111/j.1471-4159.1991.tb02558.x

Shulman, D. I., Palmert, M. R., Kemp, S. F., Lawson Wilkins, D., \& Therapeutics, C. (2007). Adrenal insufficiency: Still a cause of morbidity and death in childhood. Pediatrics, 119, e484-e494. https:// doi.org/10.1542/peds.2006-1612

Siemerling, E., \& Creutzfeldt, H. G. (1923). Bronzekrankheit und sklerosierende encephalomyelitis. Archiv Für Psychiatrie Und Nervenkrankheiten, 68, 217-244. https://doi.org/10.1007/BF018 35678

Singh, I., Khan, M., Key, L., \& Pai, S. (1998). Lovastatin for X-linked adrenoleukodystrophy. New England Journal of Medicine, 339, 702-703. https://doi.org/10.1056/NEJM199809033391012

Singh, I., \& Pujol, A. (2010). Pathomechanisms underlying X-adrenoleukodystrophy: A three-hit hypothesis. Brain Pathology, 20, 838-844. https://doi.org/10.1111/j.1750-3639.2010.00392.x

Stefan, C. J., Trimble, W. S., Grinstein, S., Drin, G., Reinisch, K., DeCamilli, P., ... Iaea, D. B. (2017). Membrane dynamics and organelle biogensis-lipid pipelines and vesicular carriers. BMC Biology, 15, 102.

Strachan, L. R., Stevenson, T. J., Freshner, B., Keefe, M. D., Miranda Bowles, D., \& Bonkowsky, J. L. (2017). A zebrafish model of $\mathrm{X}$-linked adrenoleukodystrophy recapitulates key disease features and demonstrates a developmental requirement for abcd 1 in oligodendrocyte patterning and myelination. Human Molecular Genetics, 26, 3600-3614. https://doi.org/10.1093/hmg/ddx249

Tabak, H. F., Braakman, I., \& van der Zand, A. (2013). Peroxisome formation and maintenance are dependent on the endoplasmic reticulum. Annual Review of Biochemistry, 82, 723-744. https://doi. org/10.1146/annurev-biochem-081111-125123

Theda, C. (1988). Adrenoleukodystrophie_Ergebnisse Lipidchemischer Untersuchungen im Gesamtbild der Erkrankung (Dissertation), University of Cologne, Germany.

Theda, C., Gibbons, K., Defor, T. E., Donohue, P. K., Golden, W. C., Kline, A. D., ... Raymond, G. V. (2014). Newborn screening for $\mathrm{X}$-linked adrenoleukodystrophy: Further evidence high throughput screening is feasible. Molecular Genetics and Metabolism, 111, 55-57. https://doi.org/10.1016/j.ymgme.2013.10.019

Theda, C., Moser, A. B., Powers, J. M., \& Moser, H. W. (1992). Phospholipids in X-linked adrenoleukodystrophy white matter: Fatty acid abnormalities before the onset of demyelination. Journal of the Neurological Sciences, 110, 195-204. https://doi.org/10.1016/0022510X(92)90028-J

Troffer-Charlier, N., Doerflinger, N., Metzger, E., Fouquet, F., Mandel, J. L., \& Aubourg, P. (1998). Mirror expression of adrenoleukodystrophy 
and adrenoleukodystrophy related genes in mouse tissues and human cell lines. European Journal of Cell Biology, 75, 254-264. https:// doi.org/10.1016/S0171-9335(98)80121-0

Tsuji, S., Sano, T., Ariga, T., \& Miyatake, T. (1981). Increased synthesis of hexacosanoic acid (C23:0) by cultured skin fibroblasts from patients with adrenoleukodystrophy (ALD) and adrenomyeloneuropathy (AMN). Journal of Biochemistry, 90, 1233-1236.

Turgeon, C. T., Moser, A. B., Morkrid, L., Magera, M. J., Gavrilov, D. K., Oglesbee, D., ... Tortorelli, S. (2015). Streamlined determination of lysophosphatidylcholines in dried blood spots for newborn screening of X-linked adrenoleukodystrophy. Molecular Genetics and Metabolism, 114, 46-50. https://doi.org/10.1016/j. ymgme.2014.11.013

Turk, B. R., Nemeth, C. L., Marx, J. S., Tiffany, C., Jones, R., Theisen, B., ... Fatemi, A. (2018). Dendrimer-N-acetyl-L-cysteine modulates monophagocytic response in adrenoleukodystrophy. Annals of Neurology, 84, 452-462. https://doi.org/10.1002/ana.25303

Turk, B. R., Theisen, B. E., Nemeth, C. L., Marx, J. S., Shi, X., Rosen, M., ... Fatemi, A. (2017). Antioxidant Capacity and Superoxide Dismutase Activity in Adrenoleukodystrophy. JAMA Neurol, 74, 519-524. https://doi.org/10.1001/jamaneurol.2016.5715

van de Beek, M. C., Dijkstra, I., Nagtzaam, L., Wanders, R., Van Weeghel, M., Engelen, M., \& Kemp, S. (2019). Redirecting very long chain fatty acid synthesis in adrenoleukodystrophy. Personal Communication.

van de Beek, M. C., Dijkstra, I. M., van Lenthe, H., Ofman, R. Goldhaber-Pasillas, D., Schauer, N., ... Kemp, S. (2016). C26:0carnitine is a new biomarker for $\mathrm{X}$-linked adrenoleukodystrophy in mice and man. PLOS ONE, 11, e0154597. https://doi.org/10.1371/ journal.pone.0154597

van de Beek, M. C., Ofman, R., Dijkstra, I., Wijburg, F., Engelen, M., Wanders, R., \& Kemp, S. (2017). Lipid-induced endoplasmic reticulum stress in X-linked adrenoleukodystrophy. Biochimica Et Biophysica Acta (BBA)_Molecular Basis of Disease, 1863, 22552265. https://doi.org/10.1016/j.bbadis.2017.06.003

van Engen, C. E., Ofman, R., Dijkstra, I. M., van Goethem, T. J., Verheij, E., Varin, J., ... Barbier, M. (2016). CYP4F2 affects phenotypic outcome in adrenoleukodystrophy by modulating the clearance of very long-chain fatty acids. Biochimica Et Biophysica Acta (BBA)_Molecular Basis of Disease, 1862, 1861-1870. https://doi. org/10.1016/j.bbadis.2016.07.006

van Geel, B. M., Assies, J., Haverkort, E. B., Koelman, J. H., Verbeeten, B., Jr., Wanders, R. J., \& Barth, P. G. (1999). Progression of abnormalities in adrenomyeloneuropathy and neurologically asymptomatic X-linked adrenoleukodystrophy despite treatment with "Lorenzo's oil". Journal of Neurology, Neurosurgery and Psychiatry, 67, 290-299. https://doi.org/10.1136/jnnp.67.3.290

van Geel, B. M., Bezman, L., Loes, D. J., Moser, H. W., \& Raymond, G. V. (2001). Evolution of phenotypes in adult male patients with X-linked adrenoleukodystrophy. Annals of Neurology, 49, 186-194. https://doi.org/10.1002/1531-8249(20010201)49:2<186:AIDANA38 $>3.0 . \mathrm{CO} ; 2-\mathrm{R}$

van Geel, B. M., Koelman, J.H., Barth, P. G., \& Ongerboer de Visser, B. W (1996). Peripheral nerve abnormalities in adrenomyeloneuropathy: A clinical and electrodiagnostic study. Neurology, 46, 112-118. https://doi.org/10.1212/WNL.46.1.112. [PubMed: 8559356]. van Veldhoven, P., Baes, M., \& Fransen, M. (2015). Letter to the editor: Cholesterol Transport through Lysosome-Peroxisiome Membrane Contacts: Concerns about the Unexpected Connection. Cell. https://www.cell.com/cell/comments/S0092-8674(15)00185-3

Vargas, C. R., Wajner, M., Sirtori, L. R., Goulart, L., Chiochetta, M., Coelho, D., ... Mello, C. F. (2004). Evidence that oxidative stress is increased in patients with $\mathrm{X}$-linked adrenoleukodystrophy. Biochimica Et Biophysica Acta, 1688, 26-32. https://doi. org/10.1016/j.bbadis.2003.10.004

Wanders, R. J. (2014). Metabolic functions of peroxisomes in health and disease. Biochimie, 98, 36-44. https://doi.org/10.1016/j. biochi.2013.08.022

Weinhofer, I., Zierfuss, B., Hametner, S., Wagner, M., Popitsch, N., Machacek, C., ... Berger, J. (2018). Impaired plasticity of macrophages in X-linked adrenoleukodystrophy. Brain, 141, 2329-2342. https://doi.org/10.1093/brain/awy127

Whitcomb, R. W., Linehan, W. M., \& Knazek, R. A. (1988). Effects of long-chain, saturated fatty acids on membrane microviscosity and adrenocorticotropin responsiveness of human adrenocortical cells in vitro. Journal of Clinical Investigation, 81, 185-188. https://doi. org/10.1172/JCI113292

Wiesinger, C., Eichler, F. S., \& Berger, J. (2015). The genetic landscape of X-linked adrenoleukodystrophy: Inheritance, mutations, modifier genes, and diagnosis. The Application of Clinical Genetics, 8 , $109-121$.

Wiesinger, C., Kunze, M., Regelsberger, G., Forss-Petter, S., \& Berger, J. (2013). Impaired very long-chain acyl-CoA beta-oxidation in human X-linked adrenoleukodystrophy fibroblasts is a direct consequence of ABCD1 transporter dysfunction. Journal of Biological Chemistry, 288, 19269-19279.

Xiao, J., Luo, J., Hu, A. O., Xiao, T., Li, M., Kong, Z., ... Song, B.L. (2019). Cholesterol transport through the peroxisome-ER membrane contacts tethered by $\mathrm{PI}(4,5) \mathrm{P} 2$ and extended synaptotagmins. Science China Life Sciences, 62, 1117-1135. https://doi. org/10.1007/s11427-019-9569-9

Yao, Y. K., \& Dyck, P. J. (1981). Cholesterol esterifying enzyme in normal and degenerating peripheral nerve. Journal of Neurochemistry, 37, 156-163. https://doi.org/10.1111/j.1471-4159.1981.tb053 03.x

Zackowski, K. M., Dubey, P., Raymond, G. V., Mori, S., Bastian, A. J., \& Moser, H. W. (2006). Sensorimotor function and axonal integrity in adrenomyeloneuropathy. Archives of Neurology, 63, 74-80. https ://doi.org/10.1001/archneur.63.1.74

\section{SUPPORTING INFORMATION}

Additional supporting information may be found online in the Supporting Information section.

How to cite this article: Turk BR, Theda C, Fatemi A, Moser AB. X-linked adrenoleukodystrophy: Pathology, pathophysiology, diagnostic testing, newborn screening and therapies. Int J Dev Neurosci. 2020;80:52-72. https://doi.org/10.1002/jdn.10003 


\section{University Library}

\section{- M M N E R VA A gateway to Melbourne's research publications}

Minerva Access is the Institutional Repository of The University of Melbourne

Author/s:

Turk, BR;Theda, C;Fatemi, A;Moser, AB

Title:

X-linked adrenoleukodystrophy: Pathology, pathophysiology, diagnostic testing, newborn screening and therapies.

Date:

2020-02

\section{Citation:}

Turk, B. R., Theda, C., Fatemi, A. \& Moser, A. B. (2020). X-linked adrenoleukodystrophy: Pathology, pathophysiology, diagnostic testing, newborn screening and therapies.. Int J Dev Neurosci, 80 (1), pp.52-72. https://doi.org/10.1002/jdn.10003.

Persistent Link:

http://hdl.handle.net/11343/245575

License:

CC BY 